\title{
WILEY-VCH
}

DOI: 10.1002/ ((please add manuscript number))

Article type: Full Paper

\section{Defect Passivation in Perovskite Solar Cells by Cyano-based $\pi$-conjugated Molecules for Improved Performance and Stability}

Kai Wang, * Jiang Liu, Jun Yin, Erkan Aydin, George T. Harrison, Wenzhu Liu, Shanyong Chen, Omar F. Mohammed and Stefaan De Wolf*

Dr. Kai Wang, Dr. J. Liu, Dr. E. Aydin, Dr. G. T. Harrison, Dr. W. Liu, Prof. S. De Wolf KAUST Solar Center (KSC), Physical Sciences and Engineering Division (PSE), King Abdullah University of Science and Technology (KAUST), Thuwal 23955-6900, Kingdom of Saudi Arabia.

E-mail: kai.wang@kaust.edu.sa; stefaan.dewolf@kaust.edu.sa

Dr. J. Yin, Prof. Omar F. Mohammed

Division of Physical Sciences and Engineering, King Abdullah University of Science and Technology (KAUST), Thuwal, 23955-6900, Kingdom of Saudi Arabia

Prof. S. Chen

Research Institute for New Materials Technology, Chongqing University of Arts and Sciences, Yongchuan 402160, P. R. China

Keywords: defect passivation, perovskite solar cells, conjugated molecules, increased stability

\section{Abstract}

Defects at the surface and grain boundaries of metal-halide perovskite films lead to performance losses of perovskite solar cells (PSCs). Here, we report on organic, cyano-based $\pi$-conjugated molecules composed of indacenodithieno[3,2-b]thiophene (IDTT) and find that their cyano group can effectively passivate such defects. To achieve a homogeneous distribution, we dissolved these molecules in the anti-solvent, used to initiate the perovskite crystallization. We find that these molecules are self-anchored at the grain boundaries due to their strong binding to under-coordinated $\mathrm{Pb}^{2+}$. On device level, this passivation scheme enhances the charge separation and transport at the grain boundaries due to the well-matched energetic levels between the passivant and the perovskite. Consequently, these benefits contribute directly to the achievement of power conversion efficiencies (PCE) as high as $21.2 \%$, as well as the improved environmental and thermal stability of the PSCs. Our surface 


\section{WILEY-VCH}

treatment provides a new strategy to simultaneously passivate defects and enhance charge extraction/transport at the device interface by manipulating the anchoring groups of the molecules.

\section{Introduction}

Metal-halide perovskites have attracted significant attention as a promising photovoltaic technology due to their high optical absorption coefficient, ${ }^{[1]}$ steep sub-bandgap absorption edge, ${ }^{[2]}$ long charge carrier diffusion length. ${ }^{[3]}$ To date, the PCE of lab-scale single-junction PSCs has already surpassed $25 \%$, underlining the potential of this technology to meet high device performance at a low cost. ${ }^{[4]}$ Nevertheless, solution-processed perovskite films are usually polycrystalline, featuring a high point-defect density at their surfaces and grain boundaries $(\mathrm{GB})$ including halide vacancies and undercoordinated $\mathrm{Pb}^{2+} .{ }^{[5]}$ The presence of these defects is undesirable for several reasons as they may (i) induce fast charge recombination, resulting in voltage losses at device level, (ii) contribute to fast ion migration at $\mathrm{GBs},{ }^{[6,7]}{ }^{[8]}$ (iii) create permeation pathways for oxygen and moisture, accelerating device degradation, ${ }^{[9]}$ and (iv) cause hysteresis in the current-voltage characteristic of PSCs. ${ }^{[10]}$ Therefore, passivating such defects is imperative for further improvements in PCE as well as the stability of PSCs. ${ }^{[5]}$

Numerous strategies have already been proposed for the passivation of defects in perovskites, such as the use of ionic liquids, ${ }^{[11]}$ alkali metal cations, ${ }^{[12]}$ polymers, ${ }^{[13,14]}$, selfassembled molecules ${ }^{[15]}$, and fullerene derivatives. ${ }^{[8,}$ 16] Certain organic molecules with carboxyl, amino, carbonyl, and pyridine functional groups have been explored as well due to their inherent advantages such as ease of synthesis and purification, well-defined structure, good tolerance to moisture and solution processability. ${ }^{[17]}$ Additionally, they have higher synthetic modularity than polymers, due to the symmetry requirements of the monomers used in poly-condensation reactions. ${ }^{[18]}$ Previously, Snaith et al. have reported that pyridine and 


\section{WILEY-VCH}

thiophene derivatives could passivate perovskite films via coordinate bonding with uncoordinated $\mathrm{Pb}^{2+} \cdot{ }^{[19]}$ Huang et al. have demonstrated the effectiveness of an $n$-type Lewis base (indacenodithiophene end-capped with 1,1-dicyanomethylene-3-indanone, IDIC) with carbonyl and cyano groups as an interlayer between perovskite and cathode, improving device performance and suppressing hysteresis. ${ }^{[20]}$ However, comprehensive design of the effective passivation molecule is yet to be demonstrated. To this end, the chemical modification of the organic-molecule is a straightforward and effective route to formulate the design principles for efficient passivation approach.

$\mathrm{N}$-type fused-ring organic conjugated molecules feature diverse functional groups that contain lone-pair electrons which can effectively passivate undercoordinated $\mathrm{Pb}^{2+}$; moreover, their high electron affinity may facilitate the electron extraction. ${ }^{[21]}$ Although these molecules have been utilized in organic solar cells as electron acceptors, ${ }^{[22]}$ only a few studies have been reported so far on their passivation role in PSCs. ${ }^{[23]}$ Starting from this point, we designed and synthesized two organic molecules featuring the same fused-ring indacenodithienothiophene (IDTT) as a middle core, end-capped by 4-Bromo-7-cyano-2,1,3-benzothiadiazole (labeled here SM1) and 4-Bromo-7-dicyanovinyl-2,1,3-benzothiadiazole (labeled SM2), respectively. Unlike other insulating passivators, IDTT is adopted to ensure sufficient semiconductor property of the molecules. The role of cyano groups on the passivation of mixed-cation mixed-halide perovskites $\left(\mathrm{FA}_{0.81} \mathrm{MA}_{0.14} \mathrm{Cs}_{0.05} \mathrm{PbI}_{2.55} \mathrm{Br}_{0.45}\right)$ was systematically studied due to their high reproducibility and phase stability. ${ }^{[24]}$ We demonstrate that SM2 molecule, which has two cyano groups as the end, is present throughout the entire depth of the perovskite films, suggesting its location in the grain boundaries. The density functional theory (DFT) and experimental results suggest that the SM2 molecule with two cyano groups creates a stronger binding to surface undercoordinated $\mathrm{Pb}^{2+}$ compared to the SM1 molecule (with only one cyano group), minimizing the deep trap states in the perovskite layer. Furthermore, SM2 could enhance the charge separation and transport at the perovskite $\mathrm{GB} /$ molecule interface, 


\section{WILEY-VCH}

thanks to a proper energetic alignment of its lowest unoccupied molecular orbital (LUMO) with the conduction band minimum $(\mathrm{CBM})$ of the perovskite.

Thanks to the advantages mentioned above of the SM2 molecule, we achieved a PCE of $21.1 \%$ in planar $n-i-p$ PSCs. Moreover, benefited from the grain boundary passivation by the hydrophobic small molecules, which prevents moisture penetration into perovskite film, the small molecule-treated PSCs displayed a remarkable improvement in the stability of their PCE. The SM2-treated device lost only $20 \%$ in PCE after exposure to $25 \%$ relative humidity (RH) at room temperature for $2000 \mathrm{~h}$ and $29 \%$ after $60 \mathrm{~h}$ at $80^{\circ} \mathrm{C}$ in a controlled environment. By comparison, the control sample underwent a significant decrease of $39 \%$ in PCE. These results give evidence that fine-tuning of the terminal functional group of molecules can significantly affect their passivation ability and band alignment with perovskite layers. Our experimental results and DFT calculations demonstrate the importance of molecular engineering of passivation molecules to improve device efficiency and stability, providing a new information on how to design and synthesize efficient defect-passivants.

\section{Results and Discussion}

The synthetic route of SM1 and SM2 involves a microwave-assisted Pd-mediated direct cross-coupling reaction between 4-Bromo-7-cyano-2,1,3-benzothiadiazole or 4-Bromo-7dicyanovinyl-2,1,3-benzothiadiazole and IDTT-bis-(trimethylstannane). The target molecules were purified via column chromatography and recycling size-exclusion chromatography (SEC). The SMs were dissolved in the anti-solvent chlorobenzene (CB) and were dropped on the perovskite precursor films during spin coating, followed by thermal annealing. The detailed procedure, ${ }^{1} \mathrm{H}$ NMR and ${ }^{13} \mathrm{C}$ NMR are provided in Supporting Information.

The surface morphology of the prepared perovskite films treated by SMs was investigated by scanning electron microscopy (SEM) and atomic force microscopy (AFM). As shown in Figure 1b, all top-view SEM images exhibit densely packed large grains. We assign the patch-like dark area on the surface to the aggregation of the SMs. Although SEM images did 


\section{WILEY-VCH}

not show a significant change on the crystallinity of the films after passivation, atomic force microscopy analysis revealed that passivation could result in a smoother film since the SMs might play a role in the nucleation and growth of the perovskite film during solution-casting

X-ray diffraction (XRD) patterns of perovskite films with and without SMs passivation show almost identical intensities and peak positions, revealing that the large molecules SM1 and SM2 do not distort the crystal lattice significantly. Thus, SM treatments do not affect the crystallinity and bandgap of the perovskite films, which can also be confirmed by UV-Vis absorption results (Figure S1). The characteristic peaks at $14.51^{\circ}, 20.45^{\circ}, 25.00^{\circ}, 28.85^{\circ}$, $32.26^{\circ}$, and $35.41^{\circ}$, are assigned to (100), (110), (111), (200), (210), and (211) lattice planes, respectively. ${ }^{[25]}$ Trace $\mathrm{PbI}_{2}$ was observed at $12.7^{\circ}$ from the (001) lattice planes diffraction. Excess $\mathrm{PbI}_{2}$ has been previously reported to contribute toward high device performance. ${ }^{[26]}$ The SM2-passivated perovskite film exhibits a larger peak intensity ratio of (100) to (210) compared to the control perovskite film, indicating a stronger preferential crystal orientation. Previous reports demonstrate that the passivants which enable Lewis acid-base interactions can aid in nucleation and growth of the crystallization process, leading to a better orientation of perovskite grains. ${ }^{[7,14,27]}$ 


\section{WILEY-VCH}

(a)
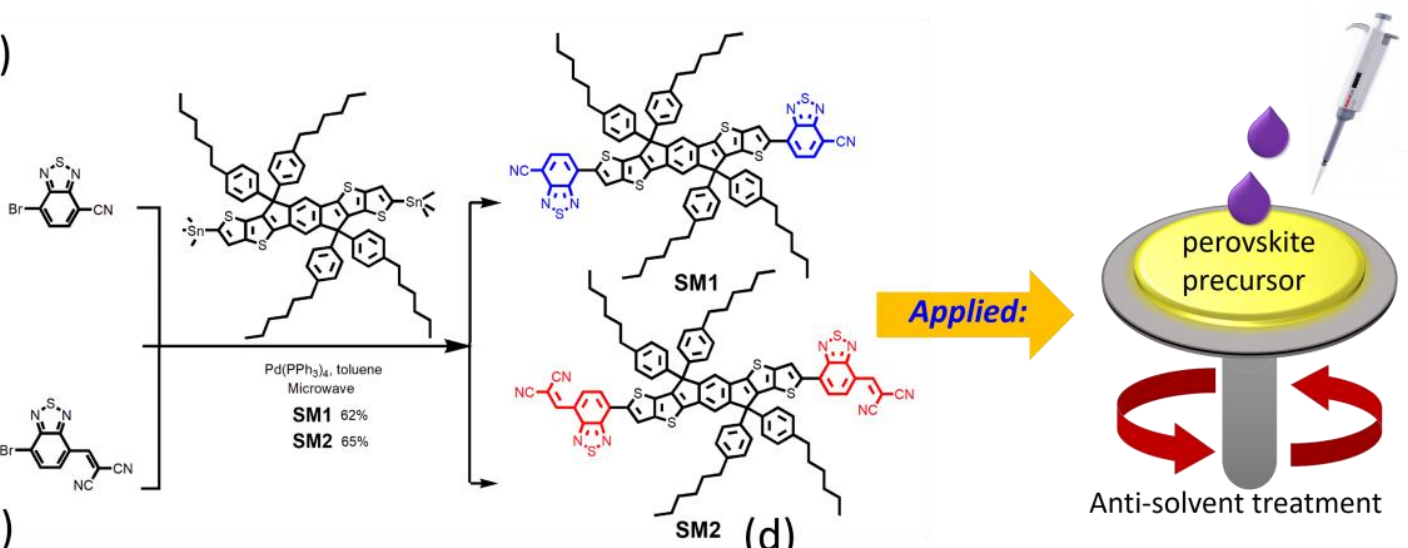

(b)

(d)

(c)
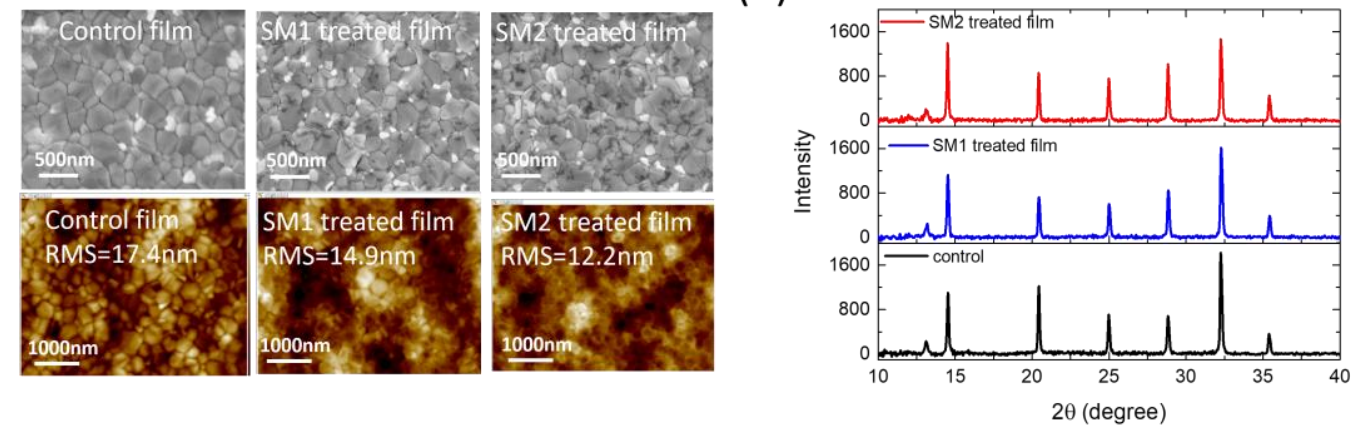

Figure 1. (a) Chemical synthesis route and chemical structures of SM1 and SM2; (b) SEM and (c) AFM characteristics of CB, SM1- and SM2-treated films; (d) XRD spectra of CB, SM1- and SM2-treated films. The root-mean-square (RMS) roughness of the films is 17.4, 14.9, and $12.2 \mathrm{~nm}$ for pristine, SM1- and SM2-treated perovskite films.

Figure 2a shows dense and uniform cross-section morphologies of the perovskite films that are composed of nearly the same crystalline grain size for the control and SM2-treated device, which is in line with the negligible change in the grain size observed in the top-view SEM. To pinpoint the distribution of the molecules through the perovskite film, we conducted crosssectional scanning transmission electron microscopy (STEM) and energy-dispersive X-ray spectroscopy (EDX) mapping on SM2-treated perovskite films in high-angle annular darkfield (HAADF) mode (Figure 2b). The homogeneous distribution of $\mathrm{Pb}$, I and $\mathrm{Cs}$ in the perovskite layer, as shown in Figure 2b, indicates a high elemental uniformity. Notably, the S element, present in the fused-thiophene unit, is an element marker for SM2, while it is absent 


\section{WILEY-VCH}

in the pristine perovskite. S element is present throughout the entire SM2-treated perovskite layer, suggesting the existence of SM2 inside the perovskite layer. Furthermore, as SM2 cannot be incorporated into the perovskite lattice due to the large size of the molecule, as evidenced by XRD analysis, the molecule most likely locates at the grain boundaries of the polycrystalline perovskite films.

To examine the interaction of the perovskite and SMs, we carried out X-ray photoelectron spectroscopy (XPS) experiments. As shown in Figure 2c, the pristine perovskite film prepared by pure $\mathrm{CB}$ washing exhibits the expected binding energy of the doublet $\mathrm{Pb} 4 \mathrm{f}_{7 / 2}$ at $138.5 \mathrm{eV}$ and $\mathrm{Pb} 4 \mathrm{f}_{5 / 2}$ at $143.3 \mathrm{eV}$, respectively. However, the perovskite films prepared by SM1- and SM2-containing anti-solvent exhibit the binding energies of $\mathrm{Pb} 4 \mathrm{f}_{7 / 2}$ at $138.2 \mathrm{eV}$ and $\mathrm{Pb} 4 \mathrm{f}_{5 / 2}$ at $143.0 \mathrm{eV}$, respectively, indicating a shift of $0.3 \mathrm{eV}$ to lower binding energies. Typically, the binding energy of a core electron level shifts to lower values when the atom acquires a higher electron density. Privitera et al. reported that the $\mathrm{Pb} 4 \mathrm{f}$ doublet decreases to a lower binding energy in the presence of Poly(3-hexylthiophene-2,5-diyl) (P3HT) due to the electronic interaction between perovskite nanoparticles and P3HT, which generates an excess of negative charges on the perovskite nanoparticles. ${ }^{[28]}$ Kyaw et al. have observed the $\mathrm{Pb} 4 \mathrm{f}$ binding energy shifted to a lower value when introducing PDTBDT-FBT solutions as antisolvent. ${ }^{[14]}$ In our case, the shift of binding energy might come from the coordination bond formed between the $\mathrm{Pb}^{2+}$ and the cyano functional unit with a high electron density.

The coordination reaction between the molecules and $\mathrm{Pb}^{2+}$ was also investigated by Fourier-transform infrared (FTIR) spectroscopy. Figure S2 shows the stretching vibration mode of the cyano $(\mathrm{C} \equiv \mathrm{N})$ bond is at $2157 \mathrm{~cm}^{-1}$ of the pristine SM2 film, while it shifts to a lower wavenumber of $2149 \mathrm{~cm}^{-1}$ in the $\mathrm{PbI}_{2}-\mathrm{SM} 2$ mixed film, indicating there is an interaction between the perovskite and molecules, and the $\mathrm{C} \equiv \mathrm{N}$ bond is weakened. To further understand the binding nature of the molecules with surface $\mathrm{Pb}$ atom, we performed density functional theory (DFT) calculations on the $\mathrm{MAPbI}_{3}$ (001) slab with $\mathrm{PbI}_{2}$-rich termination 


\section{WILEY-VCH}

after SM1 and SM2 modification. In both cases, the cyano group could bind to the surface $\mathrm{Pb}$ atoms with a negative charge localized in the cyano group (blue area) and the positive charge delocalized along the top surface layers of perovskite (red area). Such alternative negative and positive charge distribution could induce the interfacial dipole for promoting the charge transfer from perovskite to the organic layer. ${ }^{[29]}$ Differently, in the case of SM2, the double cyano groups in each terminal side of the molecule could separately bind to two adjacent surface-exposed $\mathrm{Pb}$ atoms (azimuth direction) in a bidentate mode, resulting in a much higher binding energy $\left(E_{\mathrm{b}}=0.68 \mathrm{eV}\right)$ as compared to the single, mono-dentate cyano (each terminal side of SM1 $)$ passivated surface $\left(E_{\mathrm{b}}=0.51 \mathrm{eV}\right)$. This suggests SM2 molecule can stabilize the $\mathrm{PbI}_{2}$-rich surface of perovskite through double binding cyano groups.

(a)
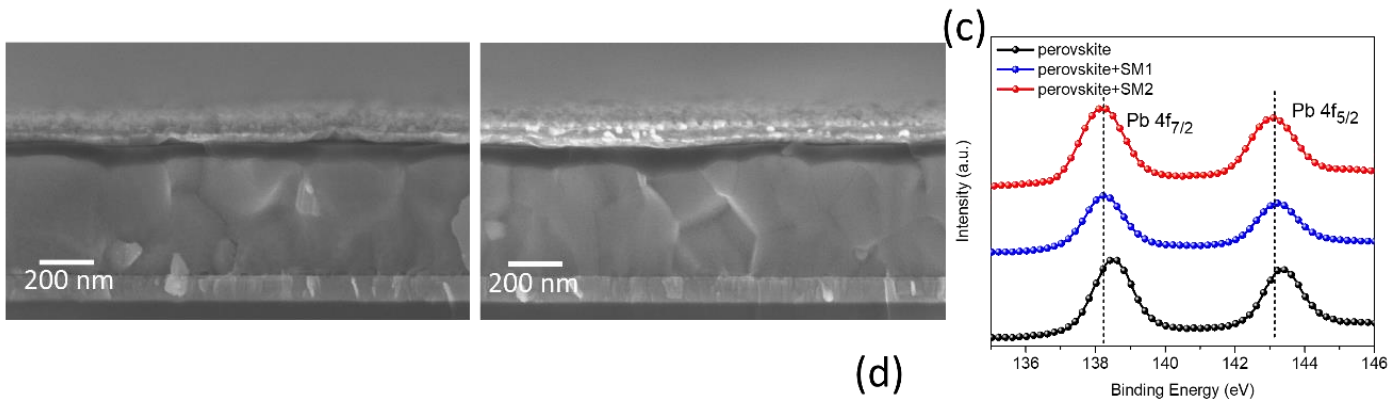

(b)
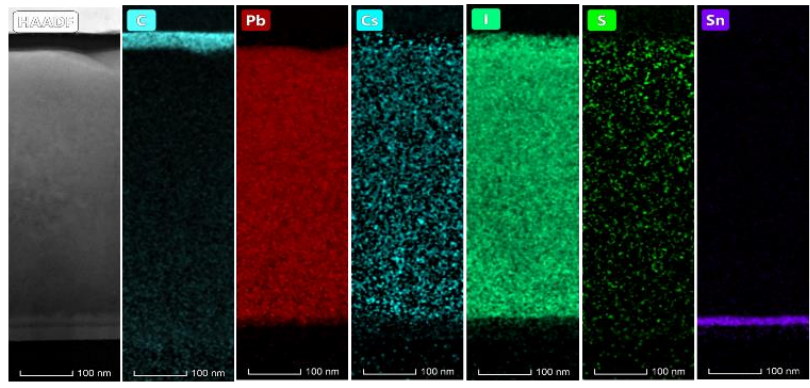

(d)

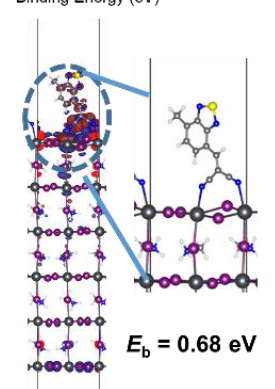

Figure 2. (a) Cross-section SEM images of PSCs with different perovskite active layer (left: without; right: with SM2 treatment); (b) Cross-sectional STEM images and the corresponding energy dispersive X-ray (EDX) elemental maps in HAADF mode for the SM2 treated device; (c) XPS of Pb 4f region of the CB, SM1, and SM2 treated-film; (d) Three-dimensional charge density differences $\left(\rho_{\text {diff }}=\rho_{\text {interface }}-\rho_{\text {perovskite }}-\rho_{\text {molecule }}\right)$ for the optimized interfacial structures of SM1 and SM2 molecule on the $\mathrm{PbI}_{2}$-terminated $\mathrm{MAPbI}_{3}$ (001) surface, together with the binding energies $\left(E_{\mathrm{b}}=E_{\text {interface }}-E_{\text {perovskite }}-E_{\text {molecule }}\right)$ calculated at the GGA/PBE level. 


\section{WILEY-VCH}

To evaluate the passivation effect of SM1 and SM2 on the solar cell performance, we fabricated regular-structure $(n-i-p)$ planar PSC devices by incorporating the molecules to perovskite layers. The fabricated device has a structure of glass/indium tin oxide (ITO)/SnO 2 /perovskite/2,2',7,7'-tetrakis(N,N-di-p-methoxyphenylamine)-9,9-spirobifluorene (Spiro-MeOTAD)/Au. The photovolatic parameters of the PSCs in different concentrations are summarized in Table S1. The optimal concentration of SM1 and SM2 is 0.1 and $0.2 \mathrm{mg}$ $\mathrm{mL}^{-1}$, respectively. Figure 3a displays the current density-voltage $(J-V)$ curves of the PSCs with and without SMs. While the control device without SMs exhibits an average PCE of $18.8 \%$ with a $V_{\text {oc }}$ of $1141 \mathrm{mV}$, a $J_{\text {sc }}$ of $23.2 \mathrm{~mA} / \mathrm{cm}^{2}$ and an $F F$ of $70.9 \%$, with an optimal concentration of SM2 in the anti-solvent solution, the devices shows significant improvement of PCE to $20.3 \%$, with a $V_{\mathrm{OC}}$ of $1169 \mathrm{mV}$, a $J_{\mathrm{SC}}$ of $23.5 \mathrm{~mA} / \mathrm{cm}^{2}$ and an $F F$ of $74.4 \%$. Besides, SM1-based devices exhibit a slight increase in PCE of 19.3\% compared to the control device, with a $V_{\mathrm{OC}}$ of $1153 \mathrm{mV}$, a $J_{\mathrm{SC}}$ of $23.3 \mathrm{~mA} / \mathrm{cm}^{2}$, and an $F F$ of $71.8 \%$. All devices exhibit negligible hysteresis in their current-voltage characteristics when scanned from different directions (Figure 3b-c). The integrated current density from EQE was calculated to be 22.1, 22.3 and $22.4 \mathrm{~mA} / \mathrm{cm}^{2}$ for the control and SM1, SM2-passivated devices, respectively, which is in line with the $J_{\text {sc }}$ obtained from the $J-V$ characterization (Figure 3d). Figure 3e shows the stabilized PCE of $20.5 \%$ and $18.7 \%$ for the optimal SM2-treated device and control device measured by the maximum power point $\left(V_{\max }\right)$ tracking under continuous illumination. The $V_{\mathrm{mpp}}$ for the control and SM2-treated PSCs is 0.91 and $0.94 \mathrm{~V}$, respectively. The reproducibility of the process is demonstrated by statistical performance data collected based on 25 devices and is exhibited in Figure 3f. The best-performing SM2-based device could reach a PCE of $21.16 \%$, with a $V_{\mathrm{oc}}$ of $1185 \mathrm{mV}$, a $J_{\mathrm{sc}}$ of $23.8 \mathrm{~mA} / \mathrm{cm}^{2}$, and an $F F$ of $75.2 \%$, underlining the beneficial effect of the SMs on device performance. The enhanced PSC performance could be attributed to the effectiveness of the grain boundary passivation of SMs. 
(a)

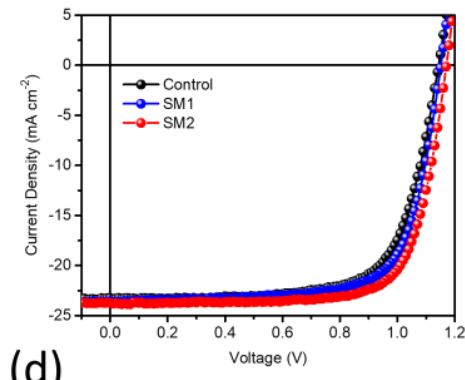

(d)

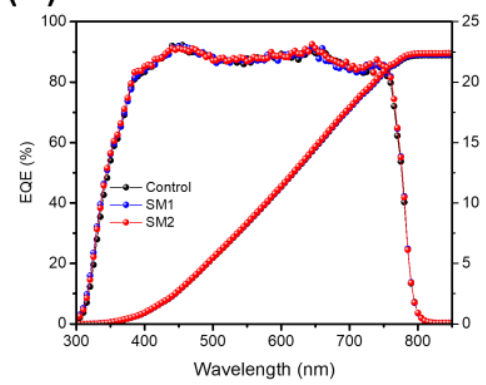

(b)

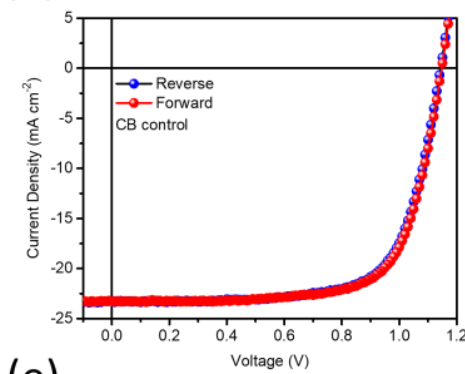

(e)

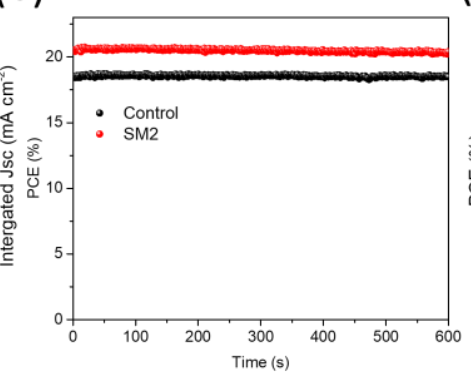

(c)

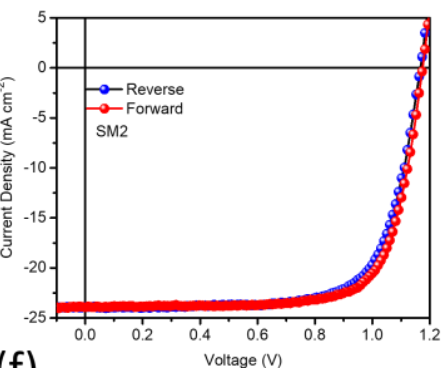

(f)

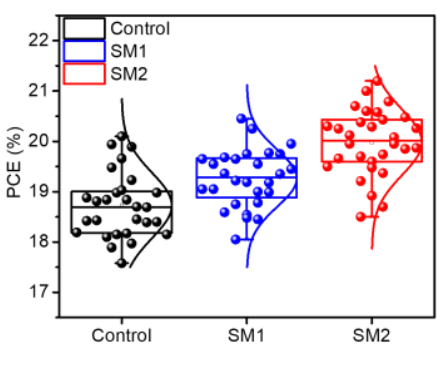

Figure 3. (a) Current density-voltage $(J-V)$ characteristics of the planar PSCs of the control devices, SM1, and SM2 treated devices using optimal concentration. Hysteresis test for the planar PSCs of (b) the control device and (c) the SM2 treated device. (d) EQE spectra for optimal control, SM1, and SM2 treated devices. (e) Stabilized PCE of optimal control and SM2 treated device. (f) Statistics of PCE of control, SM1, and SM2 treated devices from 25 individual solar cells.

Table 1. Summary of device performance parameters of PSCs of control, SM1 and SM2 treated devices.

\begin{tabular}{ccccc}
\hline Device & $\mathrm{V}_{\mathrm{OC}}[\mathrm{mV}]$ & $\mathrm{J}_{\mathrm{SC}}\left[\mathrm{mA} / \mathrm{cm}^{2}\right]$ & FF $[\%]$ & PCE [\%] \\
Control & 1141 & 23.2 & 70.9 & 18.8 \\
Control champion & 1165 & 23.5 & 74.1 & 20.2 \\
SM1 & 1153 & 23.3 & 71.8 & 19.4 \\
SM1 champion & 1176 & 23.7 & 74.4 & 20.7 \\
SM2 & 1169 & 23.5 & 73.4 & 20.3 \\
SM2 champion & 1185 & 23.8 & 75.2 & 21.2 \\
\hline
\end{tabular}

The energetic offsets present at the contacts in device stacks are generally regarded as one of the most critical parameters governing the charge extraction and transfer processes in PSCs. Ultraviolet photoelectron spectroscopy (UPS) was performed to estimate the energy levels of 


\section{WILEY-VCH}

SMs and perovskite. The $23.09 \mathrm{eV} \mathrm{UV} \mathrm{(HeI} \beta$ ) satellite has been subtracted from the spectra to better resolve the VB edge. As shown in Figure 4a-c, the work function (WF), determined by the secondary electron cut-off point, by linear extrapolation (black dashed lines), is found to be $-4.42,-4.53$ and $-4.49 \mathrm{eV}$ for perovskite, SM1, and SM2, respectively. With this, we found that $E_{W F}-E_{V B M}$ (valence band maximum) is $1.0,1.20$, and $1.0 \mathrm{eV}$ for perovskite, SM1, and SM2, respectively. The highest occupied molecular orbital (HOMO) of SM1 and SM2 HOMO can be satisfactorily found using linear extrapolation. Here the perovskite onset is determined in a semi-logarithmic intensity scale (Figure $4 \mathrm{~b}$ inset) due to the low density of states at the VBM edge as outlined by Endres et al. ${ }^{[30]}$ Taking into account the optical bands $(1.59,1.88,1.52 \mathrm{eV})$ and an assumed minimal difference between the optical and electronic gap $(10 \mathrm{meV})^{[31]}$, the perovskite has its conduction band minimum $(\mathrm{CBM})$ at $-3.83-(3.85) \mathrm{eV}$ and valence band maximum (VBM) at $-5.42(-5.4) \mathrm{eV}$. Using the band gaps of the molecules estimated from UV-vis absorption, we can calculate the positions of the lowest unoccupied molecular orbital (LUMO). Therefore, the SM1 and SM2 display HOMO of -5.73(-5.75) eV and $-5.49(-5.5) \mathrm{eV}$, and a tentative estimated LUMO of -3.85 and $-3.97(-3.95) \mathrm{eV}$ (Figure S3), respectively. The LUMO energies of both SM1 and SM2 are quite close energetically to the CBM of perovskite, suggesting preferable electron transport between adjacent perovskite grains through SM1/SM2 bridges. The relatively shallow CBM disparity of SM2 with perovskite probably could provide efficient electron transfer cascade from perovskite to $\mathrm{SnO}_{2}$.

Steady-state photoluminescence (PL) measurements were performed for the films with and without the additional treatment of the small molecules on glass $/ \mathrm{SnO}_{2}$ substrate (Figure S4). The SM2-passivated film shows more efficient PL quenching than SM1-passivated films, providing clear evidence for efficient charge separation at the interface. This observation is further confirmed at the perovskite/ $\mathrm{SnO}_{2}$ interface by time-resolved PL (TRPL) measurement (Figure 4d). The obtained parameters are shown in Table S2. The pristine perovskite film 


\section{WILEY-VCH}

exhibits $\tau_{\text {avr }}$ of $31.4 \mathrm{~ns}$, which decreased to 27.9 and $19.8 \mathrm{~ns}$ when passivated by SM1 and SM2, respectively. These results indicate the molecules passivation could lead to efficient charge separation and extraction toward the electrode, benefiting $F F$, and $V_{O C}$ improvement.

To investigate the effect of molecular passivation on the trap state density and charge mobility in perovskite films, the dark $J-V$ characteristics of so-called electron-only devices (ITO/SnO $2 /$ perovskite/[6,6]-phenyl-C61-butyric acid methyl ester (PCBM)/Au) was measured. Figure 4e illustrates the representative $J-V$ curves of the corresponding samples. The linear relation indicates an ohmic response at low bias; the current show a more rapid rise when the voltage increases over a kink point, indicative of trap filling by injected carriers. ${ }^{[32]}$ The trapstate density was calculated by the trap-filled limit voltage using the following equation ${ }^{[33]}: N_{\mathrm{t}}$ $=\frac{2 \varepsilon \varepsilon_{0} V_{\mathrm{TFL}}}{q L^{2}}$. Where $\varepsilon_{0}$ is the vacuum permittivity, $\varepsilon$ is the relative dielectric constant, $L$ is the thickness of the perovskite layer $(480 \mathrm{~nm}), q$ is the elementary charge, and $V_{\mathrm{TFL}}$ is the onset voltage of the trap-filled limit region. The $V_{\mathrm{TFL}}$ is fitted to be $0.239,0.121$, and $0.083 \mathrm{~V}$ for the control device, the SM1-treated device, and SM2-treated device, respectively. Therefore, the calculated electron trap densities are $1.62 \times 10^{16} \mathrm{~cm}^{-3}, 7.82 \times 10^{15} \mathrm{~cm}^{-3}$ and $5.71 \times 10^{15} \mathrm{~cm}^{-3}$ for the control, SM1 and SM2 passivated devices, respectively. This suggests that the trap states can be effectively passivated by SM1 and SM2, which is expected to reduce the charge recombination and benefit the FF in the solar cells. It is worth noting that SM2 shows more efficient passivation, partly due to its additional anchoring cyano group, compared to SM1. The intrinsic electron mobility was estimated from the Child's region using the space-charge limited current (SCLC) model: $J=\frac{9}{8} \varepsilon 0 \varepsilon \mu \frac{V^{2}}{L^{3}}$ and the values are shown in Figure 4f. The introduction of SM1 and SM2 increases the electron mobility to $7.14 \times 10^{-4}$ and $1.86 \times 10^{-3}$ $\mathrm{cm}^{2} \mathrm{~V}^{-1} \mathrm{~s}^{-1}$, compared to $3.22 \times 10^{-4} \mathrm{~cm}^{2} \mathrm{~V}^{-1} \mathrm{~s}^{-1}$ for the pristine film. The SM2 treatment leads to more significant improvements, consistent with the energy level cascade with the perovskite, 


\section{WILEY-VCH}

assisting more facile electron transport between adjacent perovskite grains through molecular bridge.

To understand the charge recombination of the PSCs, the light-intensity dependence of $V_{\mathrm{oc}}$ was verified. We find it can be fitted based on the equation: $V_{\mathrm{oc}}=n k T \ln (\mathrm{I}) / \mathrm{e}+\mathrm{constant}$, where $n$ is the ideal factor, $\mathrm{k}$ is the Boltzmann constant, $\mathrm{T}$ is the absolute temperature, $\mathrm{e}$ is the elementary charge, I is the fractional light intensity normalized to one sun. ${ }^{[34]}$ The slope larger than 1 indicates the presence of trap-assisted Shockley-Read-Hall (SRH) recombination. As illustrated in Figure 5a, $n$ value reduced from 1.30 for the control device to 1.12 for the SM2 passivated device, suggesting the suppression of trap-assisted carrier recombination,

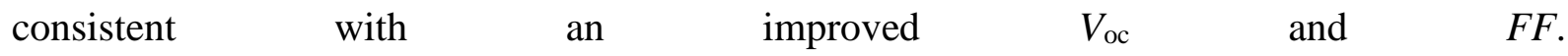

(a)

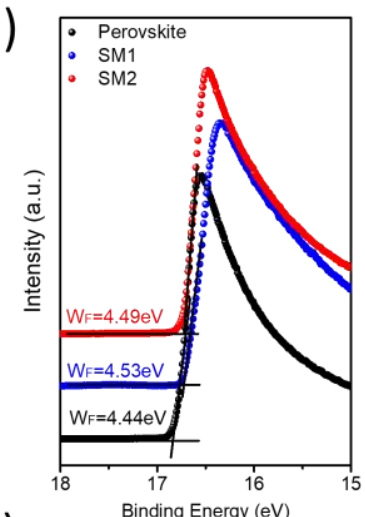

(d)

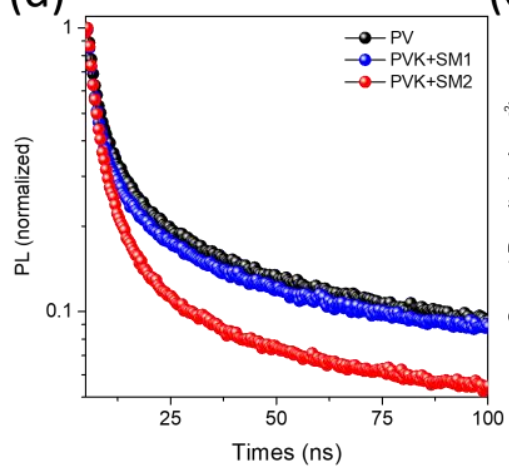

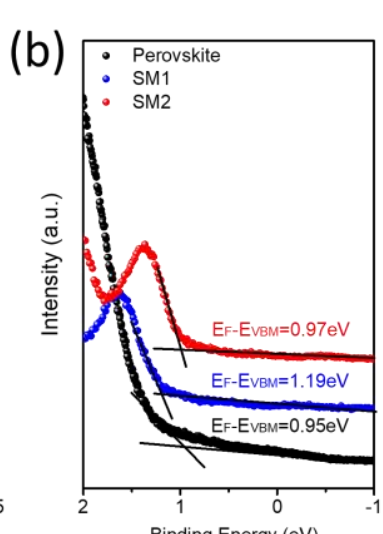

(e)

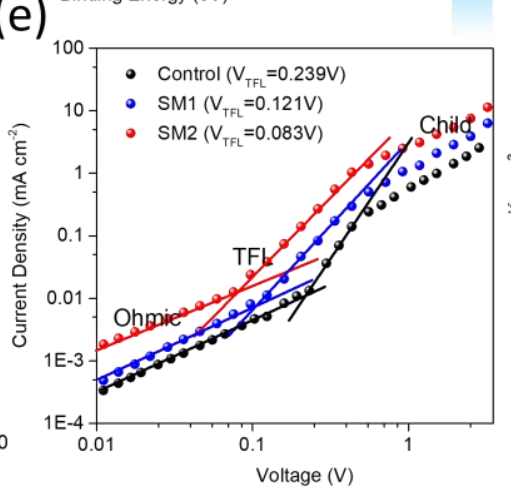

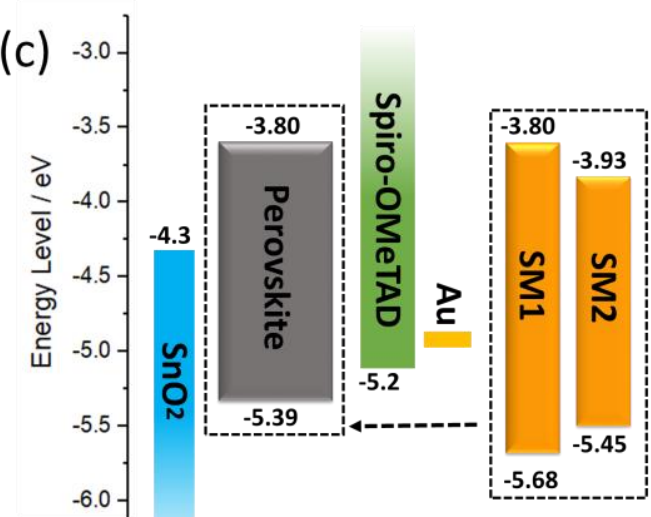

(f)

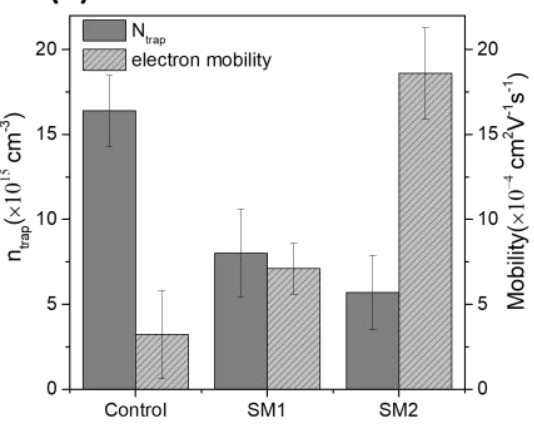

Figure 4. (a,b) UPS spectra of the perovskite, SM1 and SM2, and their work functions and VBMs can be derived, respectively inset: semi-log plot perovskite before and after removal of $\mathrm{He}(1) \beta$ line (c) Energy level diagram of the PSCs. (d) time-resolved photoluminescence (TRPL) of the control, SM1 and SM2 treated perovskite films on glass/SnO 2 substrate. (e) 


\section{WILEY-VCH}

Dark I-V measurement of the electron-only devices. Three regions can be identified to different values of the slope: $n=1$ is the Ohmic region, $n=2$ is the SCLC region and $n>2$ is the trap-filled limited region (TFL). (f) Trap density and electron mobility for the control and SMs passivated films based on 10 devices derived from SCLC measurement.

Long-term stability of PSCs is becoming an important parameter in perovskite research. ${ }^{[35]}$ Therefore, first we tested the shelf stability of the non-encapsulated devices. During the test interval, the devices were kept in a dark environment with a humidity of $\sim 25 \pm 5 \%$. Figure $5 \mathbf{b}$ shows the normalized PCE values for different devices. The PCE of the control devices degrades to $61 \%$ of its initial performance after $2000 \mathrm{~h}$, whereas perovskite solar cells with SMs passivation showed enhanced stability, maintaining $72 \%$ and $80 \%$ of its initial value for SM1 and SM2 passivated devices. Wang et al. reported that the defects at perovskite GBs initialize degradation due to the interaction of perovskite materials with moisture and oxygen. ${ }^{[36]}$ SM1 and SM2 are much more hydrophobic compared to halide perovskites. The improved stability might be attributed to the reduction of inherent defects induced by the Lewis acid-base and hydrophobic surface, rendering stronger resistance to degradation. Contact-angle tests were performed to elucidate the effect of SMs passivation to suppress moisture diffusion. The pristine perovskite film shows $\mathrm{a} \approx 34.5^{\circ}$ contact angle, while SM1 and SM2 treated perovskite films show a $71.8^{\circ}$ and $71.2^{\circ}$, respectively (Figure 5c). The improved contact angle indicates SMs can suppress moisture ingress and may lead to better stability.

We also examined the thermal stability of the devices without encapsulation at $85{ }^{\circ} \mathrm{C}$ in an $\mathrm{N}_{2}$ filled glove box. As expected, all three samples show relatively limited heat resistance. In comparison, the device with SM2 decays to $71 \%$ of its initial PCE at $c a .60 \mathrm{~h}$, while the control one decays to $52 \%$ of initial PCE. Grain boundaries can provide pathways for the rapid diffusion of atoms and ionic and are sensitive to thermal stress. Thus perovskite 


\section{WILEY-VCH}

degradation occurs mostly along the grain boundary. The defect passivation at the GBs by SMs could suppress the diffusion and enhance stability. ${ }^{[37]}$
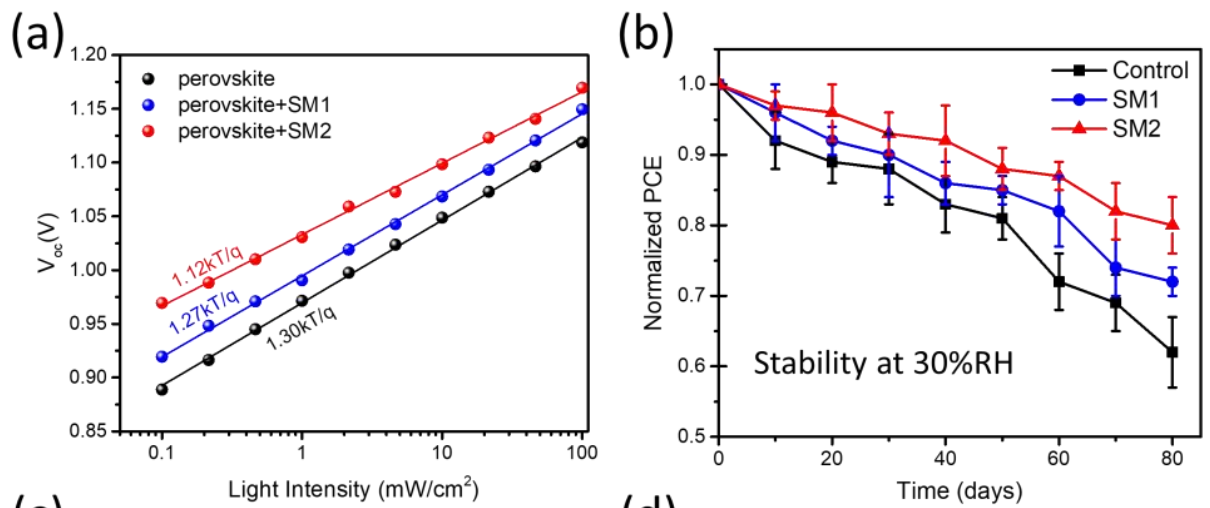

(c)

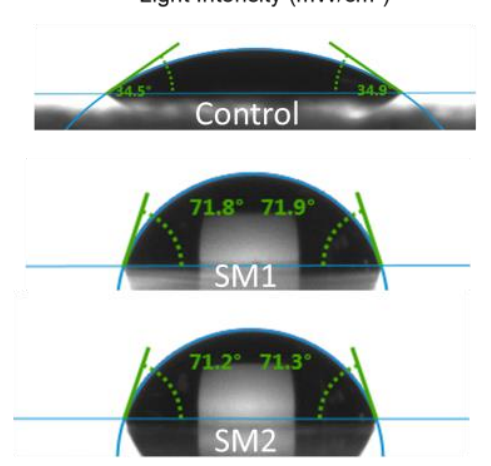

(d)

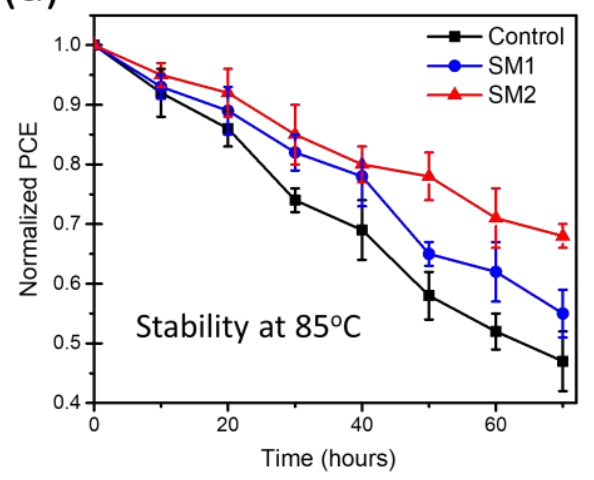

Figure 5. (a) $V_{o c}$ as a function of light intensity in a semi-log plot. (b) PCE decay of the corresponding PSCs under an ambient environment with $30 \%$ humidity in the dark at room temperature without encapsulation. (c) Static contact angle measurements with water on top of different perovskite films. (d) Recorded PCE decay of the corresponding PSCs under heating stress $\left(85^{\circ} \mathrm{C}\right)$ under an inert atmosphere.

\section{Conclusion}

In summary, we demonstrated that organic small molecules bearing varied numbers of cyano units as a terminal group could effectively passivate the defects at the surfaces and grain boundaries, leading to a significant improvement of device performance and stability. We also found that the molecules decorate grain boundary throughout the depth of the perovskite film and passivate the under-coordinated $\mathrm{Pb}^{2+}$. Importantly, $\mathrm{SM} 2$ exhibits stronger 


\section{WILEY-VCH}

bonds to the under-coordinated $\mathrm{Pb}^{2+}$ compared to $\mathrm{SM} 1$ molecule, and $\mathrm{SM} 2$ enhances the charge separation and transport at the perovskite GB/molecule interface due to the wellmatched energetic alignment with perovskite. As a result, the optimal devices incorporating SM2 exhibit significantly increased PCE up to $21.2 \%$ in planar $n-i-p$ devices, as well as improved stability at $30 \%$ relative humidity at room temperature without encapsulation and higher thermal stability under an inert atmosphere. This work provides the perovskite community a facile strategy to rationally design organic molecules to simultaneously passivate the defects and enhance the charge extraction/transportation toward highperformance perovskite solar cells with improved device stability.

\section{Experimental Section}

Perovskite Solution Preparation and Deposition: The organic cation salts methylammonium iodide (MAI), formamidinium iodide (FAI), methylammonium bromide (MABr), formamidinium bromide (FABr) were purchased from Dyesol, the lead halide compounds $\left(\mathrm{PbI}_{2}, \mathrm{PbBr}_{2}\right)$ from Sigma-Aldrich and CsI is from Alfa Aesa. Spiro-MeOTAD was purchased from Xi'an Polymer Light Technology Cory. All chemicals were used without further purification. All perovskite precursor 1.2M solution was prepared and kept overnight at $60{ }^{\circ} \mathrm{C}$ with stirring, followed by filtering by 0.45 um PTPE filter before usage. For example, the $\mathrm{FA}_{0.81} \mathrm{MA}_{0.14} \mathrm{Cs}_{0.05} \mathrm{PbI}_{2.55} \mathrm{Br}_{0.45}$ precursor solution $(1.2 \mathrm{M})$ was prepared in a molar ratio of $\mathrm{PbI}_{2} / \mathrm{PbBr}_{2}$ and $\mathrm{FAI} / \mathrm{MABr}$ both fixed at $0.85: 0.15$, and the molar ratio of $\mathrm{CsI} /(\mathrm{FAI}+\mathrm{MABr})$ at 0.05:0.95, the molar ratio of $(\mathrm{FAI}+\mathrm{MABr}+\mathrm{CsI}) /\left(\mathrm{PbI}_{2}+\mathrm{PbBr}_{2}\right)$ was $1: 1$. The $\mathrm{SnO}_{2}$ solutions is purchased from Alfa.

Solar Cell Device Fabrication and Characterizations: The solar-cell devices were fabricated using $\mathrm{SnO}_{2}$ thin-film procedure on patterned ITO-coated glass. Perovskite solutions were spin coated on top of the $\mathrm{SnO}_{2}$ layer at $2000 \mathrm{rpm}$ for $10 \mathrm{~s}$ with an acceleration of $200 \mathrm{rpm} / \mathrm{s}$. The second step was $4000 \mathrm{rpm}$ for 30s with a ramp-up of $1000 \mathrm{rpm} / \mathrm{s}$. Cholobenzene $(0.1 \mathrm{ml})$ was 


\section{WILEY-VCH}

dropped on the spinning substrate during the second spin-coating step at 10s before end of the procedure. The films were then annealed at $100{ }^{\circ} \mathrm{C}$ for $30 \mathrm{~min}$. After cooling down to room temperature, the hole-transporting layer was then deposited on top of the perovskite film via spin-coating at $4000 \mathrm{rpm}$ for $30 \mathrm{~s}$ using a chlorobenzene of a $80 \mathrm{mg} / \mathrm{ml}$ solution of $2,2^{\prime}, 7,7^{\prime}$ tetrakis-( $N, N$-di-pmethoxyphenylamine) 9,9'-spirobifluorene (spiro-MeOTAD), with additives of lithium bis(trifluoromethanesulfonyl) imide and 4-tert-butylpyridine. Finally, $80 \mathrm{~nm}$ of gold electrodes were deposited by thermal evaporation using an Angstrom evaporator. The current-density-voltage $(J-V)$ curves were measured inside the nitrogen-filled glovebox by employing ABET solar simulator system with an illumination intensity of $1000 \mathrm{~mW} / \mathrm{cm}^{2}$ (AM $1.5 \mathrm{G})$, as checked with a calibrated reference solar cell (RERA Technologies). The $J$ - $V$ curves of cells were obtained by Keithley 2400 source, on an active area of $10 \mathrm{~mm}^{2}$ for each pixel, without any pre-conditioning, at a scan rate of $380 \mathrm{mV} / \mathrm{s}$ in the voltage range from $-0.1 \mathrm{~V}$ to 1.2 V. The reversed scan (from $1.2 \mathrm{~V}$ to $-0.1 \mathrm{~V}$ ) was reported for device comparison.

Synthesis of SM1: A mixture of IDTT( $\left.\mathrm{SnMe}_{3}\right)_{2}(0.128 \mathrm{~g}, 0.09 \mathrm{mmol})$, 4-Bromo-7-cyano2,1,3-benzothiadiazole $(0.048 \mathrm{~g}, 0.20 \mathrm{mmol})$ and $\mathrm{Pd}\left(\mathrm{PPh}_{3}\right)_{4}(3.1 \mathrm{mg}, 0.03 \mathrm{eq})$ in a microwave vial was subjected to three vacuum/nitrogen cycles, and degassed toluene $(3.0 \mathrm{~mL})$ was added to the flask. The mixture was heated in a microwave reactor for $3 \mathrm{~min}$ at $120{ }^{\circ} \mathrm{C}, 3 \mathrm{~min}$ at $140{ }^{\circ} \mathrm{C}$ and $60 \mathrm{~min}$ at $175{ }^{\circ} \mathrm{C}$. The solvent was removed and the residue was subjected to column chromatography using $\mathrm{CH}_{2} \mathrm{Cl}_{2} /$ ethyl acetate (5/1) as the eluent. The product was further purified by recycling SEC $\left(\mathrm{CHCl}_{3}\right)$, yielding the product (SM1) as a black solid $(62 \%) .{ }^{1} \mathrm{H}$ NMR $\left(400 \mathrm{MHz}, \mathrm{CDCl}_{3}\right): \delta 8.73(\mathrm{~s}, 2 \mathrm{H}), 7.95(\mathrm{~d}, J=7.6 \mathrm{~Hz}, 2 \mathrm{H}), 7.77(\mathrm{~d}, J=7.6$ $\mathrm{Hz}, 2 \mathrm{H}), 7.59(\mathrm{~s}, 2 \mathrm{H}), 7.23(\mathrm{~d}, J=8.0 \mathrm{~Hz}, 8 \mathrm{H}), 7.13(\mathrm{~d}, J=8.0 \mathrm{~Hz}, 8 \mathrm{H}), 2.57(\mathrm{~m}, 8 \mathrm{H}), 1.60$ $(\mathrm{m}, 8 \mathrm{H}), 1.32(\mathrm{~m}, 24 \mathrm{H}), 0.87(\mathrm{~m}, 12 \mathrm{H}) .{ }^{13} \mathrm{C} \mathrm{NMR}\left(100 \mathrm{MHz}, \mathrm{CDCl}_{3}\right): \delta 157.15,154.19$, $153.86,151.17,149.49,148.27,146.49,143.41,142.16,141.39,139.72,135.93,128.66$, $128.05,123.06,122.95,117.57,116.89,103.98,99.94,63.16,35.60,31.69,31.25,29.15$, 22.57, 14.06. HRMS (+APCI, m/z): calcd. for $\mathrm{C}_{82} \mathrm{H}_{76} \mathrm{~N}_{6} \mathrm{~S}_{6}[\mathrm{M}+\mathrm{H}]^{+}$: 1336.45 ; found 1336.22. 


\section{WILEY-VCH}

Synthesis of SM2: A mixture of IDTT( $\left(\mathrm{SnMe}_{3}\right)_{2}$ (0.128 g, $\left.0.09 \mathrm{mmol}\right)$, 4-Bromo-7dicyanovinyl-2,1,3-benzothiadiazole $(0.06 \mathrm{~g}, 0.20 \mathrm{mmol})$ and $\mathrm{Pd}\left(\mathrm{PPh}_{3}\right)_{4}(3.1 \mathrm{mg}, 0.03 \mathrm{eq})$ in a microwave vial was subjected to three vacuum/nitrogen cycles, and degassed toluene (3.0 $\mathrm{mL}$ ) was added to the flask. The mixture was heated in a microwave reactor for $3 \mathrm{~min}$ at $120{ }^{\circ} \mathrm{C}, 3 \mathrm{~min}$ at $140{ }^{\circ} \mathrm{C}$ and $60 \mathrm{~min}$ at $175^{\circ} \mathrm{C}$. The solvent was removed and the residue was subjected to column chromatography using $\mathrm{CH}_{2} \mathrm{Cl}_{2} /$ ethyl acetate (10/1) as the eluent. The product was further purified by recycling SEC $\left(\mathrm{CHCl}_{3}\right)$, yielding the product (SM2) as a dark green solid (65\%). ${ }^{1} \mathrm{H}$ NMR (400 MHz, $\left.\mathrm{CDCl}_{3}\right): \delta 8.75(\mathrm{~s}, 4 \mathrm{H}), 8.64(\mathrm{~d}, J=8.0 \mathrm{~Hz}, 2 \mathrm{H}), 7.80$ $(\mathrm{d}, J=8.0 \mathrm{~Hz}, 2 \mathrm{H}), 7.62(\mathrm{~s}, 2 \mathrm{H}), 7.25(\mathrm{~d}, J=8.0 \mathrm{~Hz}, 8 \mathrm{H}), 7.15(\mathrm{~d}, J=8.0 \mathrm{~Hz}, 8 \mathrm{H}), 2.58(\mathrm{~m}$, 8H), $1.56(\mathrm{~m}, 8 \mathrm{H}), 1.27(\mathrm{~m}, 24 \mathrm{H}), 0.85(\mathrm{~m}, 12 \mathrm{H}) .{ }^{13} \mathrm{C} \mathrm{NMR}\left(100 \mathrm{MHz}, \mathrm{CDCl}_{3}\right): \delta$ 154.41, $151.97,150.90,147.30,146.78,143.80,142.18,139.60,136.89,136.50,134.48,133.50$, $130.63,128.73,127.99,125.27,123.71,121.36,117.56,113.96,113.22,81.73,63.06,35.61$, 31.69, 31.26, 29.16, 22.58, 14.07. HRMS (+APCI, m/z): calcd. for $\mathrm{C}_{88} \mathrm{H}_{78} \mathrm{~N}_{8} \mathrm{~S}_{6}[\mathrm{M}+\mathrm{H}]^{+}$: 1438.47; found 1438.32.

Thin film characterization: A Nikon LV-100 optical microscope was used to obtain the optical microscopy images. SEM images were taken using Nano-SEM with in-lens detector using a $10 \mathrm{kV}$ accelerating voltage and a $5 \mathrm{~mm}$ working distance. X-Ray diffraction (XRD) analysis was performed on a Bruker D8 Advance X-ray powder diffractometer using the CuK $\alpha$ radiation $(\lambda=1.54071 \AA$ ). Atomic force microscope (AFM) from Bruker was used to image the perovskite absorber layers morphology. Surface and cross-sectional images of the samples were taken by a Carl Zeiss AURIGA CrossBeam workstation using in-lens detectors. A $5 \mathrm{kV}$ voltage was used to accelerate the electrons, and the working distance was $5 \mathrm{~mm}$. The surface work function of DPO layer was measured by ultraviolet photoelectron spectroscopy (UPS). Absorption and transmission spectra were recorded by a Perkin-Elmer Lambda 950 with an integrating sphere. EQE spectra were gained through the measurement of solar cell 


\section{WILEY-VCH}

spectra response measurement system QE-R3011 (Enli Technology Ltd., Taiwan). Ultraviolet photo-electron (UPS) measurements were performed in an Omicron multi-probe UHV chamber equipped with a ISE-5 cold cathode ion gun for sputter cleaning $\left(\mathrm{Ar}^{+}\right)$a monochromated $\mathrm{Al} \mathrm{K} \mathrm{K}_{\alpha} 1486.6 \mathrm{eV}$ X-ray ( $0.75 \mathrm{~mm}$ diameter spot) source and a hemispherical electron analyzer (Sphera II) with photo-electrons collected at 90 degrees with respect to the sample plane. The UPS source was a non-attenuated He(1) lamp $\left(500 \mathrm{~V}, 90 \mathrm{~mA}, 5 \times 10^{2}\right.$ mbar) of energy $21.22 \mathrm{eV}$. The $\mathrm{He}(1) \beta 23.09 \mathrm{eV}$ emission line of $2.5 \%$ intensity (observed at a metallic fermi edge) to $\mathrm{He}(1) \alpha 21.22 \mathrm{eV}$ was subtracted from spectra prior to analysis. The analyzer system's Fermi level was determined using a clean evaporated silver sample (carbon below XPS noise level), and the sample placed in electrical contact by mounting with tight Ta clips to the sample holder. All UPS spectra were recorded with an analyzer spot of $60 \mu \mathrm{m}$, diameter and constant analyzer retarding pass energy of $5 \mathrm{eV}$ at $0.01 \mathrm{eV} / \mathrm{s}$ sweep rate. The secondary electron cut-off and the valence band onset were determined by linear extrapolation from the slope of onsets inter-section with the baseline. The Transmission Electron Miscroscopy (TEM) and Scanning transmission electron miscroscopy (STEM) images were taken by a FEI Themis- $Z$ transmission electron microscope operated at 300kV. Energy Dispersive X-ray Spectroscopy studies were performed with a Bruker super-X EDS detector. TEM lamellas were prepared on an FEI Helios G4 FIB/SEM dual-beam system equipped with $\mathrm{a} \mathrm{Ga}^{+}$ion source. $\mathrm{C} / \mathrm{Pt}$ layers were deposited on the surface region of interest by Electron\&Ion beam for sample protection. Samples were thinned down to a relative thickness of $80 \mathrm{~nm}$ using progressively decreasing ion beam energies in the FIB down to $5 \mathrm{keV}$.

Computational details: Density functional theory (DFT) calculations were carriered out by the projector-augmented wave (PAW) method using Vienna Ab initio Simulation Package (VASP). The generalized gradient approximation (GGA) with Perdew-Burke-Ernzerhof (PBE) method was used to optimize the crystal structure of tetragonal-phase $\mathrm{MAPbI}_{3}$ bulk and (001) 


\section{WILEY-VCH}

slabs. The wave functions were expanded on a plane-wave basis set up to a kinetic energy cutoff of $500 \mathrm{eV}$. The van der Waals functional vdW-DF2 was also included in the structural optimizations and electronic calculations. Monkhorst-Pack-type K-meshes of $6 \times 6 \times 4$ for the bulk tetragonal-phase $\mathrm{MAPbI}_{3}$ and $4 \times 4 \times 1$ for the slab exposing the (001) surface with SM1 or SM2 modification were used. All the structures were optimized until the forces on each single atom were $<0.01 \mathrm{eV} / \AA$. Three-dimensional charge density differences were defined as $\rho_{\text {diff }}=\rho_{\text {interface }}-\rho_{\text {perovskite }}-\rho_{\text {molecule }}$, where $\rho_{\text {interface }}$ is the total charge density of the interface after SM1 or SM2 modification, and $\rho_{\text {perovskite }}$ and $\rho_{\text {molecule }}$ represent the charge densities of the individual parts. The molecular graphics viewer VESTA was used to plot the crystal structures and charge densities.

\section{Supporting Information}

Supporting Information is available from the Wiley Online Library or from the author.

\section{Acknowledgements}

This work supported by the King Abdullah University of Science and Technology (KAUST) Office of Sponsored Research (OSR) under award no. KAUST OSR-CARF URF/1/ 3079-3301.

Received: ((will be filled in by the editorial staff)) Revised: ((will be filled in by the editorial staff)) Published online: ((will be filled in by the editorial staff)) 


\section{WILEY-VCH}

\section{References}

[1] S. De Wolf, J. Holovsky, S. J. Moon, P. Loper, B. Niesen, M. Ledinsky, F. J. Haug, J. H. Yum, C. Ballif, J Phys Chem Lett 2014, 5, 1035.

[2] M. Ledinsky, T. Schönfeldová, J. Holovsky, E. Aydin, Z. Hájková, L. Landová, N. Neykova, A. Fejfar, S. De Wolf, J Phys Chem Lett 2019.

[3] S. D. Stranks, G. E. Eperon, G. Grancini, C. Menelaou, M. J. P. Alcocer, T. Leijtens, L. M. Herz, A. Petrozza, H. J. Snaith, Science 2013, 342, 341; B. Chen, S.-W. Baek, Y. Hou, E. Aydin, M. De Bastiani, B. Scheffel, A. Proppe, Z. Huang, M. Wei, Y.-K. Wang, E.-H. Jung, T. G. Allen, E. Van Kerschaver, F. P. García de Arquer, M. I. Saidaminov, S. Hoogland, S. De Wolf, E. H. Sargent, Nat. Commun.s 2020, 11, 1257.

[4] ; A. Kojima;, K. Teshima;, Y. Shirai;, T. Miyasaka, J. Am. Chem. Soc. 2009, 131, 6050; N. J. Jeon, J. H. Noh, W. S. Yang, Y. C. Kim, S. Ryu, J. Seo, S. I. Seok, Nature 2015, 517, 476; B.-W. P. Woon Seok Yang, Eui Hyuk Jung, Nam Joong Jeon, Young Chan Kim, Dong Uk Lee, Seong Sik Shin, Jangwon Seo, Eun Kyu Kim, Jun Hong Noh, Sang Il Seok, Science 2017, 356, 1376; K. Wang, M. C. Tang, H. X. Dang, R. Munir, D. Barrit, M. De Bastiani, E. Aydin, D. M. Smilgies, S. De Wolf, A. Amassian, Adv. Mater. 2019, 31, 1808357.

[5] H. Wei, Y. Fang, P. Mulligan, W. Chuirazzi, H.-H. Fang, C. Wang, B. R. Ecker, Y. Gao, M. A. Loi, L. Cao, J. Huang, Nat. Photonics 2016, 10, 333; M. I. Saidaminov, A. L. Abdelhady, B. Murali, E. Alarousu, V. M. Burlakov, W. Peng, I. Dursun, L. Wang, Y. He, G. Maculan, A. Goriely, T. Wu, O. F. Mohammed, O. M. Bakr, Nat. Commun. 2015, 6, 7586; E. Aydin, M. De Bastiani, S. De Wolf, Adv. Mater. 2019, 31, 1900428.

[6] X. Zhu, S. Zuo, Z. Yang, J. Feng, Z. Wang, X. Zhang, S. Priya, S. F. Liu, D. Yang, ACS Appl. Mater. Interfaces 2018, 10, 39802.

[7] T. Niu, J. Lu, R. Munir, J. Li, D. Barrit, X. Zhang, H. Hu, Z. Yang, A. Amassian, K. Zhao, S. F. Liu, Adv. Mater. 2018, 30, 1706576. 


\section{WILEY-VCH}

[8] F. Deschler, M. Price, S. Pathak, L. E. Klintberg, D. D. Jarausch, R. Higler, S.

Huttner, T. Leijtens, S. D. Stranks, H. J. Snaith, M. Atature, R. T. Phillips, R. H. Friend, J. Phys. Chem. Lett. 2014, 5, 1421; X. Zheng, B. Chen, J. Dai, Y. Fang, Y. Bai, Y. Lin, H. Wei, Xiao C. Zeng, J. Huang, Nature Energy 2017, 2, 17102.

[9] Z. Wang, A. Pradhan, M. A. Kamarudin, M. Pandey, S. S. Pandey, P. Zhang, C. H.

Ng, A. S. M. Tripathi, T. Ma, S. Hayase, ACS Appl. Mater. Interfaces 2019, 11, 10012; A.

Abate, M. Saliba, D. J. Hollman, S. D. Stranks, K. Wojciechowski, R. Avolio, G. Grancini, A. Petrozza, H. J. Snaith, Nano. Lett. 2014, 14, 3247.

[10] D. Zhao, M. Sexton, H.-Y. Park, G. Baure, J. C. Nino, F. So, Adv. Energy Mater. $\mathbf{2 0 1 5}, 5,1401855$.

[11] J.-Y. Seo, T. Matsui, J. Luo, J.-P. Correa-Baena, F. Giordano, M. Saliba, K. Schenk, A. Ummadisingu, K. Domanski, M. Hadadian, A. Hagfeldt, S. M. Zakeeruddin, U. Steiner, M. Grätzel, A. Abate, Adv. Energy Mater. 2016, 6, 1600767.

[12] W. Zhao, Z. Yao, F. Yu, D. Yang, S. F. Liu, Adv. Sci. 2018, 5, 1700131; J. T.-W. Wang, Z. Wang, S. Pathak, W. Zhang, D. W. deQuilettes, F. Wisnivesky-Rocca-Rivarola, J. Huang, P. K. Nayak, J. B. Patel, H. A. Mohd Yusof, Y. Vaynzof, R. Zhu, I. Ramirez, J. Zhang, C. Ducati, C. Grovenor, M. B. Johnston, D. S. Ginger, R. J. Nicholas, H. J. Snaith, Energy Environ. Sci. 2016, 9, 2892.

[13] L. Qin, L. Wu, B. Kattel, C. Li, Y. Zhang, Y. Hou, J. Wu, W.-L. Chan, Adv. Funct. Mater. 2017, 27, 1704173; J. Jiang, Q. Wang, Z. Jin, X. Zhang, J. Lei, H. Bin, Z.-G. Zhang, Y. Li, S. F. Liu, Adv. Energy Mater. 2018, 8, 1701757; C.-C. Zhang, M. Li, Z.-K. Wang, Y.R. Jiang, H.-R. Liu, Y.-G. Yang, X.-Y. Gao, H. Ma, J. Mater. Chem. A 2017, 5, 2572; F. Tan, H. Tan, M. I. Saidaminov, M. Wei, M. Liu, A. Mei, P. Li, B. Zhang, C. S. Tan, X. Gong, Y. Zhao, A. R. Kirmani, Z. Huang, J. Z. Fan, R. Quintero-Bermudez, J. Kim, Y. Zhao, O. Voznyy, Y. Gao, F. Zhang, L. J. Richter, Z. H. Lu, W. Zhang, E. H. Sargent, Adv. Mater. 


\section{WILEY-VCH}

2019, 31, 1807435; W. Chen, Y. Wang, G. Pang, C. W. Koh, A. B. Djurišić, Y. Wu, B. Tu, F. z. Liu, R. Chen, H. Y. Woo, X. Guo, Z. He, Adv. Funct. Mater. 2019, 1808855.

[14] X. Li, W. Li, Y. Yang, X. Lai, Q. Su, D. Wu, G. Li, K. Wang, S. Chen, X. W. Sun, A.

K. K. Kyaw, Solar RRL 2019, 3, 1900029.

[15] Y. Hou, E. Aydin, M. De Bastiani, C. Xiao, F. H. Isikgor, D.-J. Xue, B. Chen, H.

Chen, B. Bahrami, A. H. Chowdhury, A. Johnston, S.-W. Baek, Z. Huang, M. Wei, Y. Dong, J. Troughton, R. Jalmood, A. J. Mirabelli, T. G. Allen, E. Van Kerschaver, M. I. Saidaminov, D. Baran, Q. Qiao, K. Zhu, S. De Wolf, E. H. Sargent, Science 2020, 367, 1135.

[16] F. Zhang, W. Shi, J. Luo, N. Pellet, C. Yi, X. Li, X. Zhao, T. J. S. Dennis, X. Li, S. Wang, Y. Xiao, S. M. Zakeeruddin, D. Bi, M. Gratzel, Adv. Mater. 2017, 29, 1606806; Y. Shao, Z. Xiao, C. Bi, Y. Yuan, J. Huang, Nat. Commun. 2014, 5, 5784.

[17] T. Wu, Y. Wang, X. Li, Y. Wu, X. Meng, D. Cui, X. Yang, L. Han, Adv. Energy Mater. 2019, 9, 1803766; E. H. Jung, N. J. Jeon, E. Y. Park, C. S. Moon, T. J. Shin, T. Y. Yang, J. H. Noh, J. Seo, Nature 2019, 567, 511; J. Peng, J. I. Khan, W. Liu, E. Ugur, T. Duong, Y. Wu, H. Shen, K. Wang, H. Dang, E. Aydin, X. Yang, Y. Wan, K. J. Weber, K. R. Catchpole, F. Laquai, S. De Wolf, T. P. White, Adv. Energy Mater. 2018, 8, 1801208.

[18] K. Wang, Y. Firdaus, M. Babics, F. Cruciani, Q. Saleem, A. El Labban, M. A. Alamoudi, T. Marszalek, W. Pisula, F. Laquai, P. M. Beaujuge, Chem. Mater. 2016, 28, 2200; K. Wang, M. Neophytou, E. Aydin, M. Wang, T. Laurent, G. T. Harrison, J. Liu, W. Liu, M. De Bastiani, J. I. Khan, T. D. Anthopoulos, F. Laquai, S. De Wolf, Adv. Mater. Interfaces 2019, 6, 1900434.

[19] A. A. N. Noel, S. Stranks, E. Parrott, V. Burlakov, A. Goriely, H. Snaith, ACS Nano, $8,9815$.

[20] Y. Lin, L. Shen, J. Dai, Y. Deng, Y. Wu, Y. Bai, X. Zheng, J. Wang, Y. Fang, H. Wei, W. Ma, X. C. Zeng, X. Zhan, J. Huang, Adv. Mater. 2016, 1604545. 


\section{WILEY-VCH}

[21] C. Yan, S. Barlow, Z. Wang, H. Yan, A. K. Y. Jen, S. R. Marder, X. Zhan, Nat. Rev. Mater. 2018, 3, 18003.

[22] M. Zhang, X. Zhan, Adv. Energy Mater. 2019, 9, 1900860.

[23] M. Zhang, S. Dai, S. Chandrabose, K. Chen, K. Liu, M. Qin, X. Lu, J. M. Hodgkiss, H. Zhou, X. Zhan, J. Am. Chem. Soc. 2018, 140, 14938; J. Cheng, H. Zhang, S. Zhang, D. Ouyang, Z. Huang, M. K. Nazeeruddin, J. Hou, W. C. H. Choy, J. Mater. Chem. A 2018, 6, 23865.

[24] K. Wang, M.-C. Tang, H. X. Dang, R. Munir, D. Barrit, M. De Bastiani, E. Aydin, D.M. Smilgies, S. De Wolf, A. Amassian, Advanced Materials 2019, 31, 1808357; H. X. Dang, K. Wang, M. Ghasemi, M.-C. Tang, M. De Bastiani, E. Aydin, E. Dauzon, D. Barrit, J. Peng, D.-M. Smilgies, S. De Wolf, A. Amassian, Joule 2019.

[25] L. Chen, Y. Y. Tan, Z. X. Chen, T. Wang, S. Hu, Z. A. Nan, L. Q. Xie, Y. Hui, J. X. Huang, C. Zhan, S. H. Wang, J. Z. Zhou, J. W. Yan, B. W. Mao, Z. Q. Tian, J. Am. Chem. Soc. 2019, 141, 1665.

[26] B. W. Park, N. Kedem, M. Kulbak, D. Y. Lee, W. S. Yang, N. J. Jeon, J. Seo, G. Kim, K. J. Kim, T. J. Shin, G. Hodes, D. Cahen, S. I. Seok, Nat. Commun. 2018, 9, 3301.

[27] L. Zhu, Y. Xu, P. Zhang, J. Shi, Y. Zhao, H. Zhang, J. Wu, Y. Luo, D. Li, Q. Meng, J. Mater. Chem. A 2017, 5, 20874.

[28] A. Privitera, M. Righetto, M. De Bastiani, F. Carraro, M. Rancan, L. Armelao, G. Granozzi, R. Bozio, L. Franco, J. Phys. Chem. Lett. 2017, 8, 5981.

[29] J. Yin, D. Cortecchia, A. Krishna, S. Chen, N. Mathews, A. C. Grimsdale, C. Soci, The journal of physical chemistry letters 2015, 6, 1396.

[30] J. Endres, D. A. Egger, M. Kulbak, R. A. Kerner, L. Zhao, S. H. Silver, G. Hodes, B. P. Rand, D. Cahen, L. Kronik, A. Kahn, The Journal of Physical Chemistry Letters 2016, 7, 2722. 


\section{WILEY-VCH}

[31] A. Miyata, A. Mitioglu, P. Plochocka, O. Portugall, J. T.-W. Wang, S. D. Stranks, H. J. Snaith, R. J. Nicholas, Nature Physics 2015, 11, 582; Y. Yang, M. Yang, Z. Li, R. Crisp, K. Zhu, M. C. Beard, J Phys Chem Lett 2015, 6, 4688.

[32] D. Shi, V. Adinolfi, R. Comin, M. Yuan, E. Alarousu, A. Buin, C. Y, S. Hoogland, A. Rothenberger, K. Katsiev, Y. Losovyj, X. Zhang, P. Dowben, O. Mohammed, E. H. Sargent, O. M. Bakr, Science 2015, 347, 519.

[33] R. H. Bube, J. Appl. Phys. 1962, 33, 1733.

[34] W. L. Leong, Z. E. Ooi, D. Sabba, C. Yi, S. M. Zakeeruddin, M. Graetzel, J. M. Gordon, E. A. Katz, N. Mathews, Adv. Mater. 2016, 28, 2439.

[35] M. V. Khenkin, E. A. Katz, A. Abate, G. Bardizza, J. J. Berry, C. Brabec, F. Brunetti, V. Bulović, Q. Burlingame, A. Di Carlo, R. Cheacharoen, Y.-B. Cheng, A. Colsmann, S. Cros, K. Domanski, M. Dusza, C. J. Fell, S. R. Forrest, Y. Galagan, D. Di Girolamo, M. Grätzel, A. Hagfeldt, E. von Hauff, H. Hoppe, J. Kettle, H. Köbler, M. S. Leite, S. Liu, Y.-L. Loo, J. M. Luther, C.-Q. Ma, M. Madsen, M. Manceau, M. Matheron, M. McGehee, R. Meitzner, M. K. Nazeeruddin, A. F. Nogueira, Ç. Odabaşı, A. Osherov, N.-G. Park, M. O. Reese, F. De Rossi, M. Saliba, U. S. Schubert, H. J. Snaith, S. D. Stranks, W. Tress, P. A. Troshin, V. Turkovic, S. Veenstra, I. Visoly-Fisher, A. Walsh, T. Watson, H. Xie, R. Yıldırım, S. M. Zakeeruddin, K. Zhu, M. Lira-Cantu, Nat. Energy 2020, 5, 35.

[36] F. Wang, W. Geng, Y. Zhou, H. H. Fang, C. J. Tong, M. A. Loi, L. M. Liu, N. Zhao, Adv. Mater. 2016, 28, 9986.

[37] Y. Yuan, J. Huang, Acc. Chem. Res. 2016, 49, 286. 


\section{WILEY-VCH}

Copyright WILEY-VCH Verlag GmbH \& Co. KGaA, 69469 Weinheim, Germany, 2016.

\section{Supporting Information}

Defect Passivation in Perovskite Solar Cells by Cyano-based $\pi$-conjugated Molecules for Improved Performance and Stability

Kai Wang, * Jiang Liu, Jun Yin, Erkan Aydin, George T. Harrison, Wenzhu Liu, Shanyong Chen, Omar F. Mohammed and Stefaan De Wolf*

Dr. Kai Wang, Dr. J. Liu, Dr. E. Aydin, Dr. G. T. Harrison, Dr. W. Liu, Prof. S. De Wolf KAUST Solar Center (KSC), Physical Sciences and Engineering Division (PSE), King Abdullah University of Science and Technology (KAUST), Thuwal 23955-6900, Kingdom of Saudi Arabia.

E-mail: kai.wang@kaust.edu.sa; stefaan.dewolf@kaust.edu.sa

Dr. J. Yin, Prof. Omar F. Mohammed

Division of Physical Sciences and Engineering, King Abdullah University of Science and Technology (KAUST), Thuwal, 23955-6900, Kingdom of Saudi Arabia

Prof. S. Chen

Research Institute for New Materials Technology, Chongqing University of Arts and Sciences, Yongchuan 402160, P. R. China 


\section{WILEY-VCH}

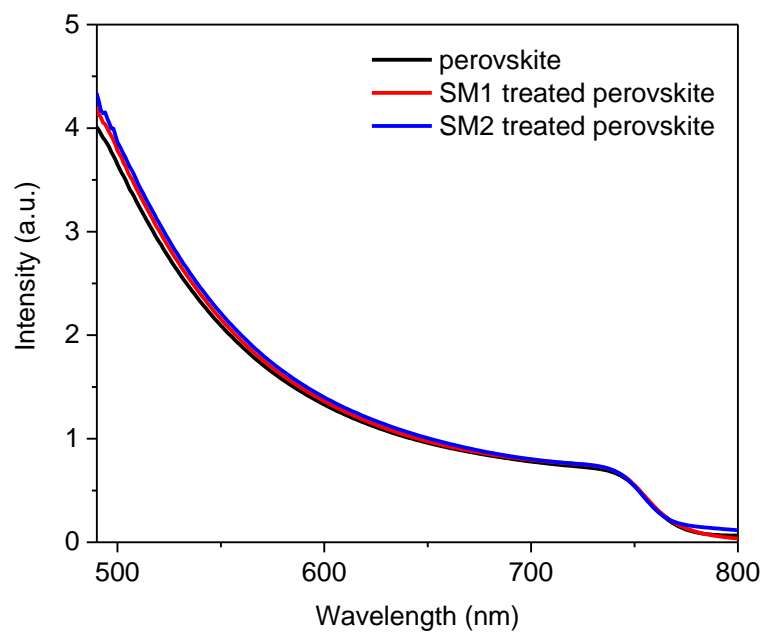

Figure S1. UV-Vis absorption spectra of perovskite, SM1 treated perovskite and SM2 treated perovskite

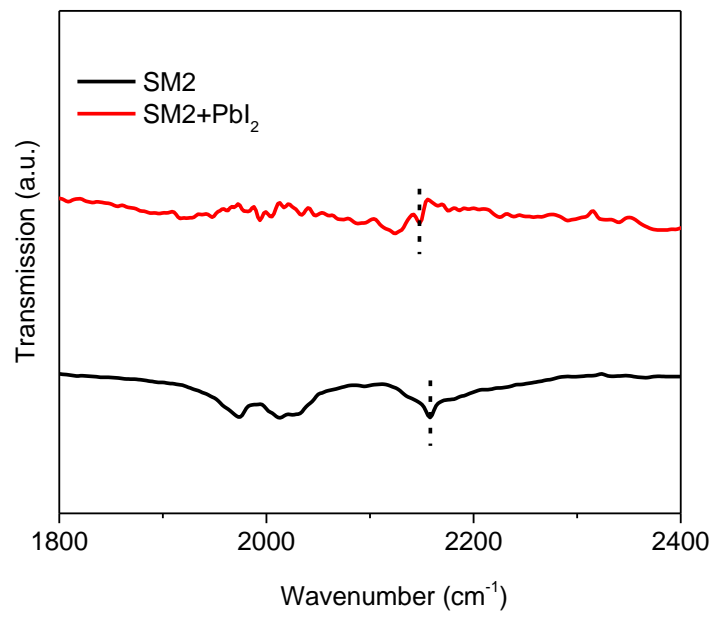

Figure S2. Fourier transform infrared spectra (FTIR) of pure SM2 and $\mathrm{SM} 2-\mathrm{PbI}_{2}$ mixture. 


\section{WILEY-VCH}

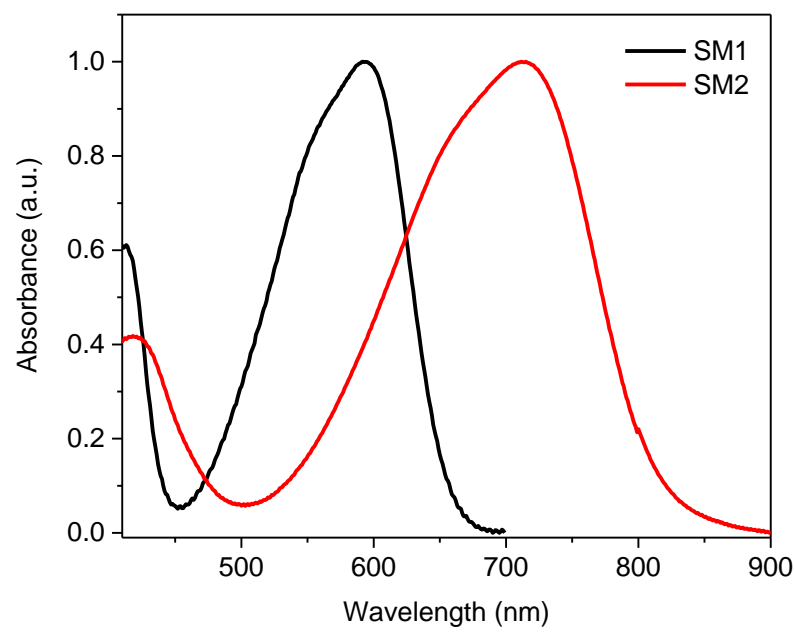

Figure S3. UV-Vis absorption spectra of pure SM1 and SM2 thin film.

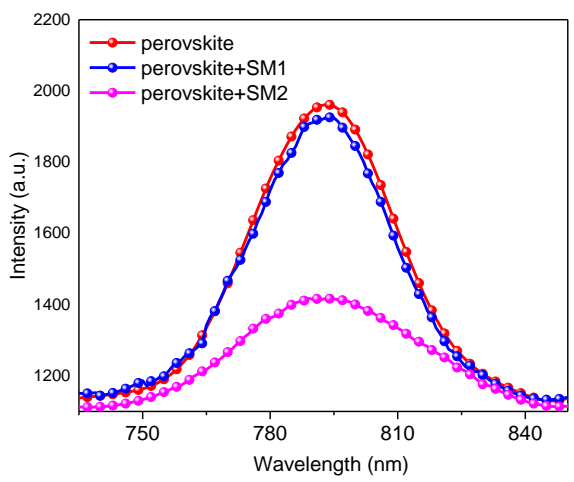

Figure S4. Room temperature steady-state photoluminescence spectra for perovskite, perovskite treated with SM1 and SM2 on glass $/ \mathrm{SnO}_{2}$ substrate. 


\section{WILEY-VCH}

Table S1. Photovoltaic parameters of PSCs of SM1 and SM2 in different concentrations.

\begin{tabular}{cccccc}
\hline & {$\left[\mathrm{mg} \mathrm{mL}^{-1}\right]$} & $\mathrm{V}_{\mathrm{OC}}[\mathrm{mV}]$ & $\mathrm{J}_{\mathrm{SC}}\left[\mathrm{mA} / \mathrm{cm}^{2}\right]$ & $\mathrm{FF}[\%]$ & PCE [\%] \\
\hline SM1 & 0.05 & 1146 & 23.2 & 71.2 & 18.9 \\
& 0.1 & 1176 & 23.7 & 74.4 & 20.7 \\
& 0.2 & 1153 & 22.8 & 72.1 & 19.0 \\
& 0.3 & 1144 & 22.7 & 70.4 & 18.3 \\
\hline SM2 & 0.1 & 1165 & 23.5 & 73.9 & 20.3 \\
& 0.2 & 1185 & 23.8 & 75.2 & 21.2 \\
& 0.3 & 1159 & 23.2 & 72.3 & 19.4 \\
& 1148 & 23.0 & 70.8 & 18.7 \\
& & & & \\
& & & & & \\
\end{tabular}

We estimated the hysteresis index $(\mathrm{HI})$ by the relation of $\mathrm{HI}=\left[J_{\mathrm{RS}}\left(0.8 \mathrm{~V}_{\mathrm{oc}}\right)-J_{\mathrm{FS}}\left(0.8 \mathrm{~V}_{\mathrm{oc}}\right)\right] /$ $J_{\mathrm{RS}}\left(0.8 \mathrm{~V}_{\mathrm{oc}}\right)$, where $J_{\mathrm{RS}}\left(0.8 \mathrm{~V}_{\mathrm{oc}}\right)$ and $J_{\mathrm{FS}}\left(0.8 \mathrm{~V}_{\text {oc }}\right)$ denote photocurrent density measured from the reverse scan and forward scan at $\mathrm{V}=0.8 \mathrm{~V}$, respectively. The average $\mathrm{HI}$ was calculated from 25 devices for each condition and the average $\mathrm{HI}$ is 0.027 and 0.015 for the control device and SM2 treated device, respectively. This slightly reduced hysteresis could be attributed to the suppressed ion migration benefited from the grain boundary passivation, consistent with the previous report.

Table S2. Summary of lifetime parameter from Time-Resolved PL spectra by fitting with biexponential decay function.

$f(\mathrm{t})=\Sigma A_{i} \exp \left(-t / \tau_{i}\right)+\mathrm{B}$

\begin{tabular}{cccccc}
\hline & $\tau_{1}(\mathrm{~ns})$ & $\mathrm{A}_{1}(\%)$ & $\tau_{2}(\mathrm{~ns})$ & $\mathrm{A}_{2}(\%)$ & $\tau_{\text {avg }}(\mathrm{ns})$ \\
Perovskite & 3.22 & 19.7 & 31.42 & 80.2 & 31.4 \\
Perovskite+SM1 & 3.13 & 21.8 & 28.63 & 73.2 & 27.9
\end{tabular}




\section{WILEY-VCH}

$\begin{array}{llllll}\text { Perovskite+SM2 } & 2.70 & 34.3 & 20.92 & 65.7 & 19.8\end{array}$

$\tau_{\text {avg }}$ is calculated from the equation $\tau_{\text {avg }}=\frac{\sum A_{i} \tau_{i}^{2}}{\sum A_{i} \tau_{i}}$

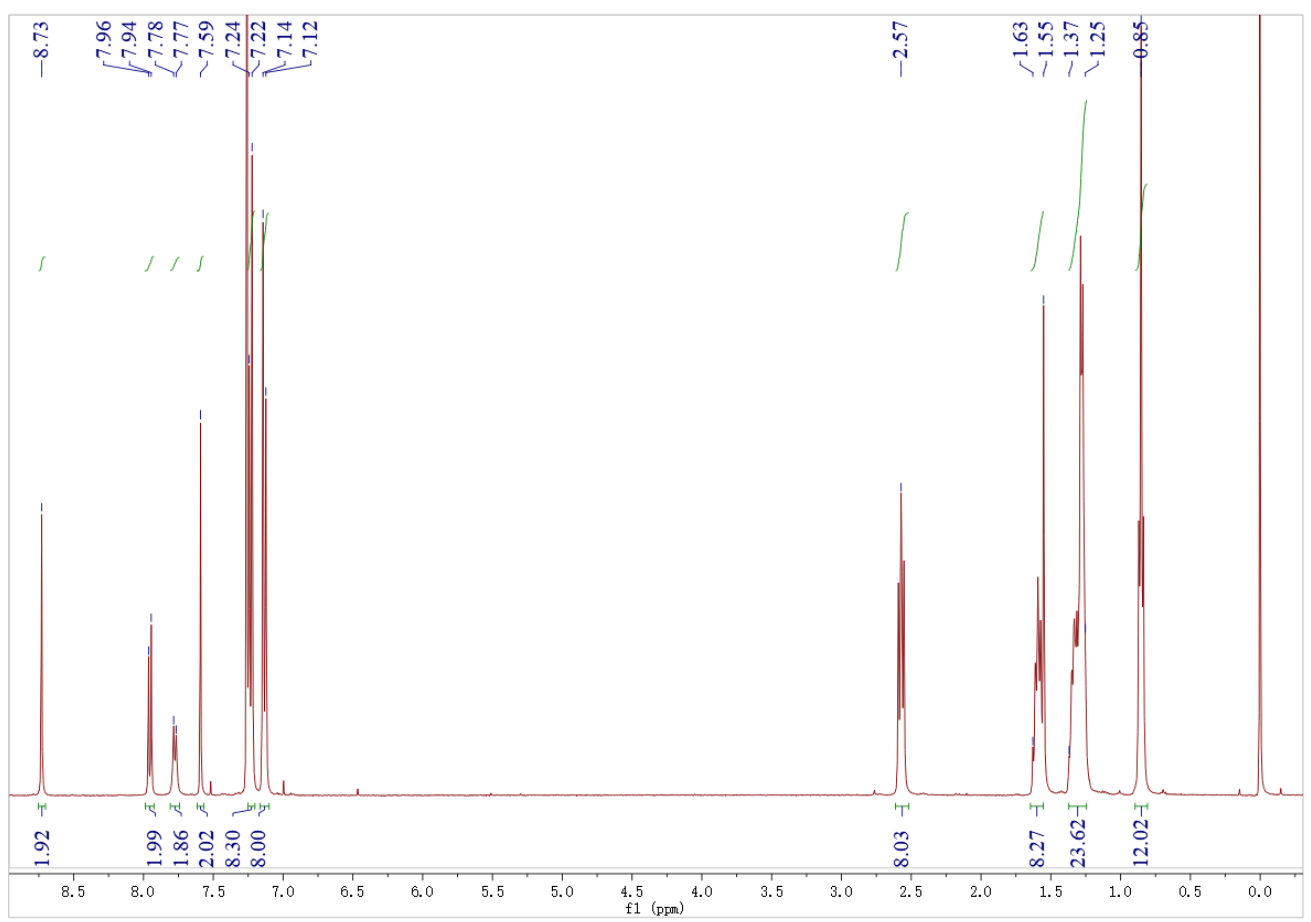

Figure S5. ${ }^{1} \mathrm{H}$ NMR spectrum of SM1. 


\section{WILEY-VCH}

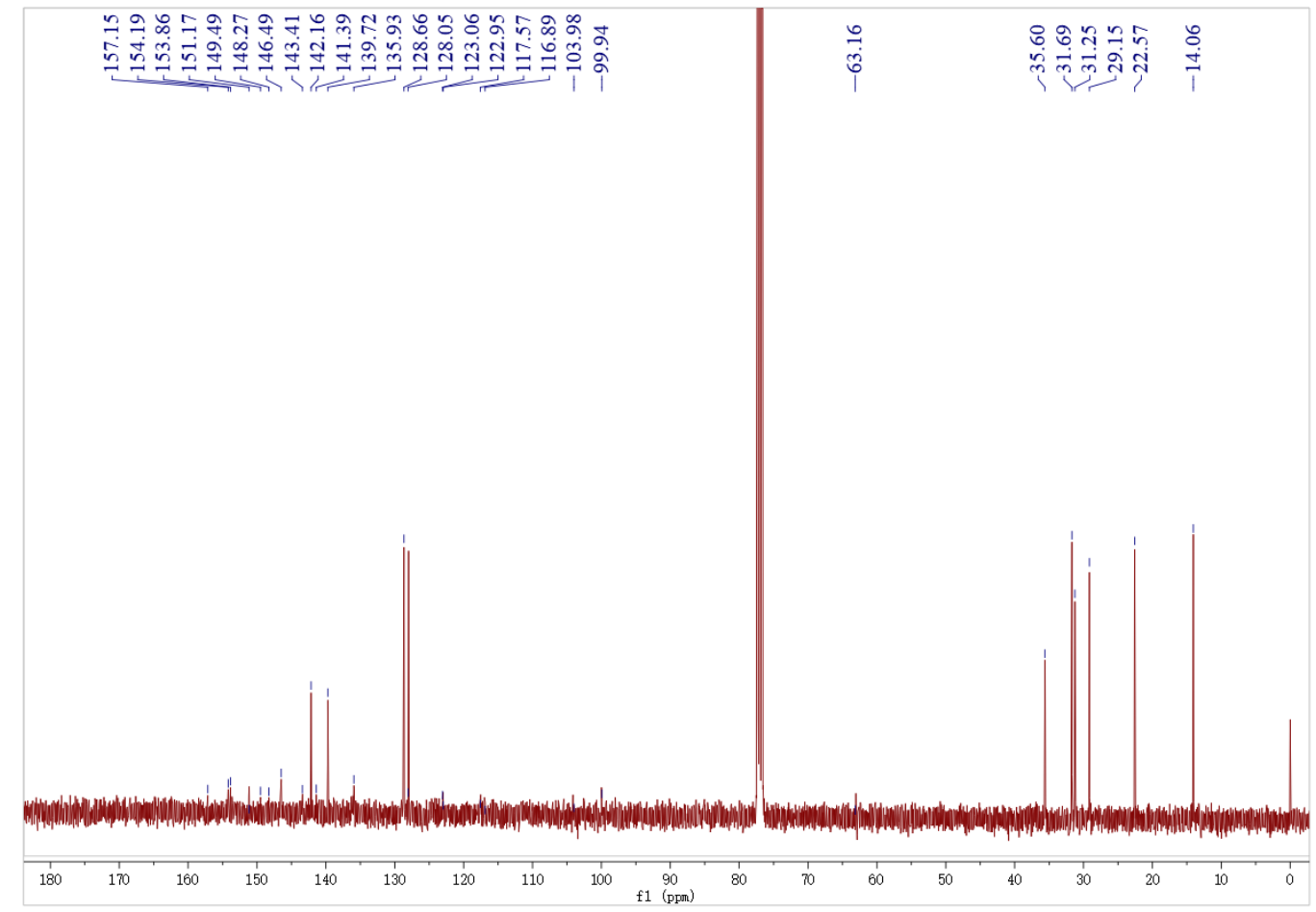

Figure S6. ${ }^{13} \mathrm{C}$ NMR spectrum of SM1.

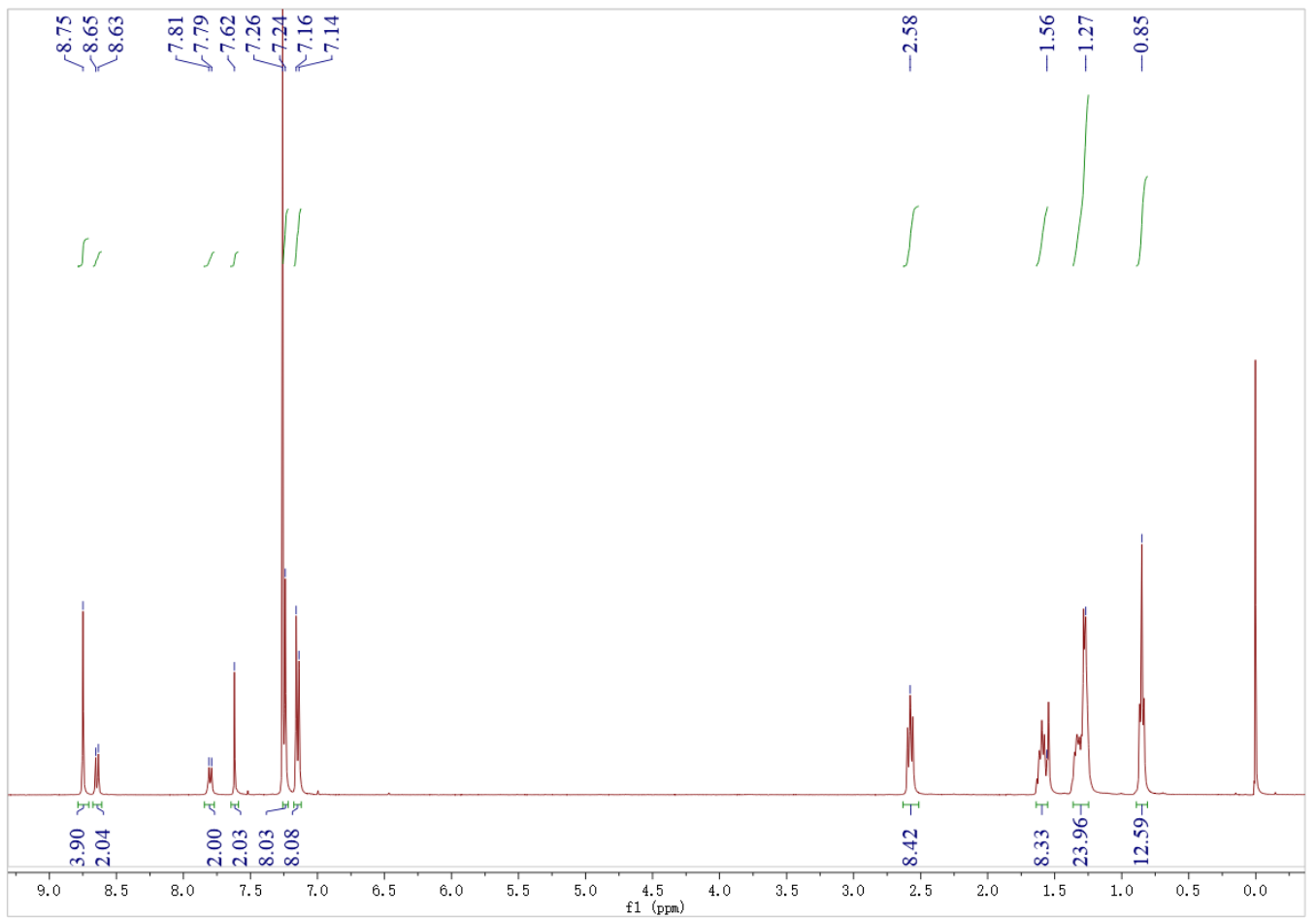

Figure S7. ${ }^{1} \mathrm{H}$ NMR spectrum of SM2. 


\section{WILEY-VCH}

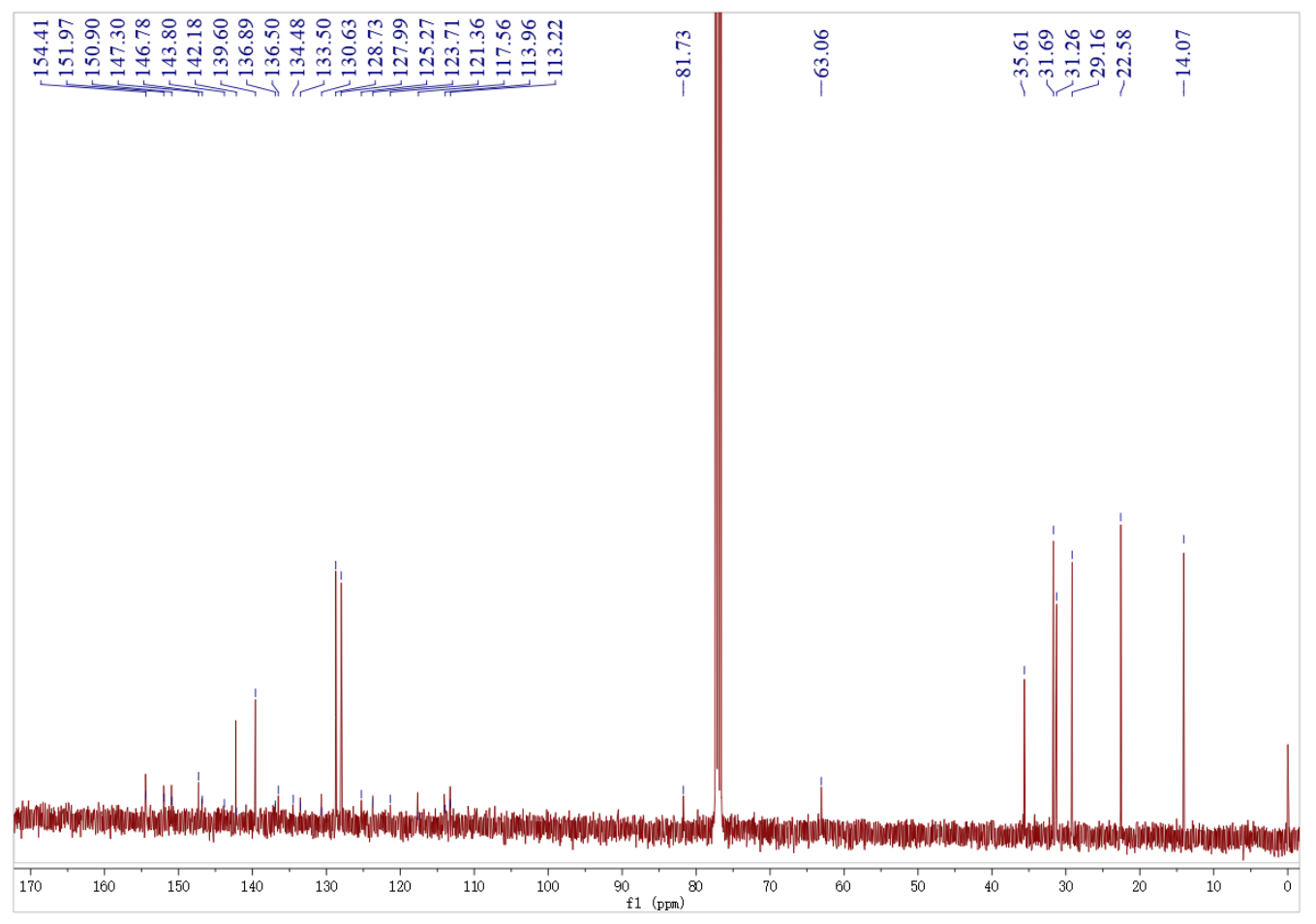

Figure S8. ${ }^{13} \mathrm{C}$ NMR spectrum of SM2. 
The table of contents

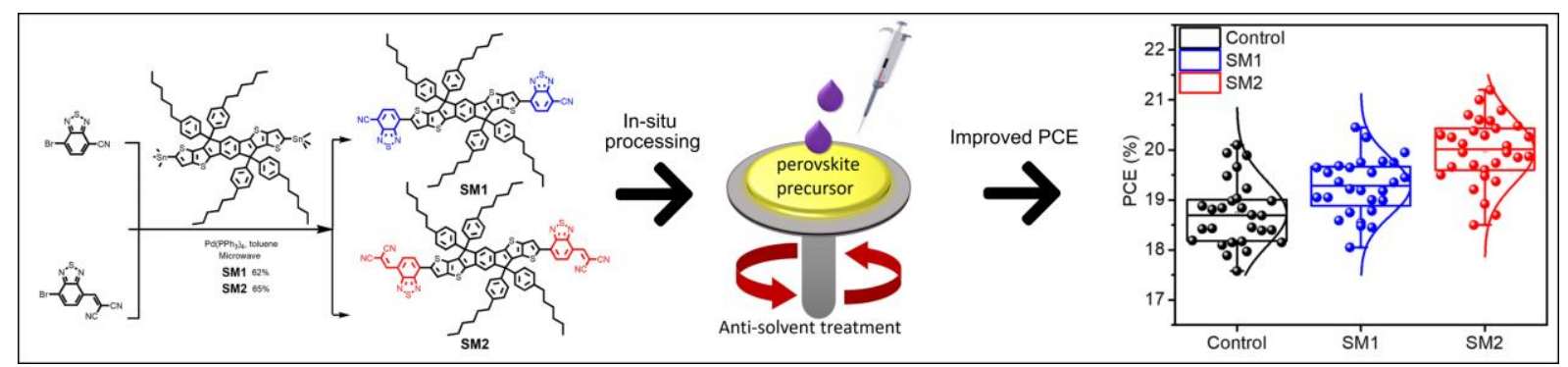

Cyano-based $\pi$-conjugated molecules composed of indacenodithieno[3,2-b]thiophene

(IDTT) and the cyano group are used to passivate the defect at the surface and grain boundaries of metal-halide perovskite films. These molecules are self-anchored at the grain boundaries due to their strong binding to under-coordinated $\mathrm{Pb}^{2+}$ and enhanced the power conversion efficiencies up to $21.2 \%$, with improved stability of the perosvkite solar cells. 